\title{
Genera Acremonium and Sarocladium Cause Brown Spot on Bagged Apple Fruit in China
}

\author{
Y. M. Hou, ${ }^{1}$ X. Zhang, ${ }^{1}$ N. N. Zhang, ${ }^{1}$ W. Naklumpa, ${ }^{1}$ W. Y. Zhao, ${ }^{1}$ X. F. Liang, ${ }^{1}$ R. Zhang, ${ }^{1, \dagger}$ G. Y. Sun, ${ }^{1,}$ and M. L. Gleason ${ }^{2}$ \\ ${ }^{1}$ State Key Laboratory of Crop Stress Biology in Arid Areas and College of Plant Protection, Northwest A\&F University, \\ Yangling, Shaanxi Province, China \\ ${ }^{2}$ Department of Plant Pathology and Microbiology, Iowa State University, Ames, IA, U.S.A.
}

\begin{abstract}
Apple fruit spot disease has caused serious economic losses for years in China since the widespread application of fruit bagging in production. Although the three genera Trichothecium, Alternaria, and Acremonium have been reported to be the causal agents, studies on the disease etiology and pathogen biology are still sparse. Here, we report characterization of eight fungal isolates from lesions on 126 symptomatic fruit samples collected in Shaanxi Province, China. Pathogenicity of the isolates was assessed. DNA sequences were obtained at four loci, including D1/D2 domains of the large-subunit nrRNA gene, internal transcribed spacer regions 1 and 2, 5.8S nrDAN gene, a fragment of the actin gene, and a fragment of the $\beta$-tubulin. Based on phylogenetic analysis and morphological features, three new species were found: Acremonium mali, Sarocladium

liquanensis, and Sarocladium mali. In addition, we made the first report of Sarocladium terricola as a plant pathogen. Temperature and moisture significantly affected in vitro conidial germination of five Acremonium-like species, and their impact on infection of apple fruit was tested using Acremonium sclerotigenum. Conidia of five species germinated from 15 to $35^{\circ} \mathrm{C}$ in free water; four of the species had optimum temperature around $25^{\circ} \mathrm{C}$, whereas conidia of $S$. terricola had an optimum temperature of $30^{\circ} \mathrm{C}$. Conidial germination rate increased as relative humidity $(\mathrm{RH})$ increased. The five isolates had relatively high conidial germination rates at $\mathrm{RH}>97 \%$, with a significant decline at $95 \% \mathrm{RH}$. Incidence of infection also increased in proportion to RH. In free water, conidial germination was relatively unaffected by temperature.
\end{abstract}

In China, covering apples with fruit bags from May to October is a widely used production technology. The bags can protect apple fruit from pests and rain-dispersed pathogens, and they can also reduce pesticide residues at harvest. However, this change of fruit microenvironment has led to the emergence of fruit spot disease in China. Black spot disease on apple fruit was first observed in 2000 in Tianshui and Longnan districts of Gansu Province (Xu et al. 2000), and it was later discovered in most of the production areas in Shaanxi, Shandong, and Hebei Provinces (Wang et al. 2007). Incidence levels ranged from 3 to $60 \%$ in these areas, and in one case, they reached $90 \%$ (Guo et al. 2005), causing serious economic losses. A brown spot disease affecting apple in Shandong Province caused 1 to $30 \%$ annual yield losses in most orchards from 2010 to 2012 (Li et al. 2014).

Several factors seem to influence incidence of fruit spot disease. The widely grown cultivar Fuji was the most susceptible. Rainfall showed a significant positive correlation with fruit spot incidence (Li et al. 2015). Disease incidence dropped significantly when airpermeable fruit bags were used. All of these studies indicated that temperature and moisture inside the fruit bags may have significant impact on disease incidence (Dai et al. 2019; Li et al. 2015; Wang et al. 2007).

Apple fruit spot can be caused by a wide range of fungal species, and the symptoms also vary with the predominant causal agents and apple cultivars. Cylindrosporium pomi and Phoma pomi, which cause green brown spots with red haloes, were detected in Gansu Province (Xu et al. 2000), whereas Trichothecium roseum,

${ }^{\dagger}$ Corresponding authors: R. Zhang; rongzh@nwsuaf.edu.cn, and G. Y. Sun; sgy@nwsuaf.edu.cn

Funding: This research was supported by National Natural Science Foundation of China (31772113); China Agriculture Research System Project (CARS-27); and Shaanxi Provincial Science Research and Development Program (2016KTZDNY03-04-02)

The author(s) declare no conflict of interest.

Accepted for publication 13 February 2019.

C 2019 The American Phytopathological Society
Acremonium stictum, and Alternaria spp. caused black or brown spots on apple fruit in Shaanxi Province (Guo et al. 2005). In Shandong Province, Acremonium sclerotigenum was reported as the causal agent of brown spot disease (Li et al. 2014).

The objective of this study was to characterize the diversity of brown spot pathogens in Shaanxi Province. Orchard surveys were carried out from 2014 to 2016. The impact of temperature and relative humidity $(\mathrm{RH})$ on conidial germination and disease incidence was also characterized.

\section{Materials and Methods}

Sampling areas and isolation technique. One hundred twentysix symptomatic apple fruits were collected from 19 orchards in Liquan, Qianxian, Wugong, and Yangling districts of Shaanxi Province, China, from 2014 to 2016. Sampled fruit were rinsed with sterile water, air dried, and surface sterilized with $75 \%$ ethyl alcohol for $30 \mathrm{~s}$ followed by rinsing with sterile water and air drying under aseptic conditions. Tissue samples $\left(0.5 \mathrm{~cm}^{3}\right)$ from the margins of brown spot lesions were transferred to potato dextrose agar (PDA) in a sterile environment and incubated at $25^{\circ} \mathrm{C}$ for 1 week in darkness, and pure cultures were obtained by singlespore transfer (Wiseman et al. 2015). Pure isolates were stored in $20 \%$ glycerol at $-80^{\circ} \mathrm{C}$.

The representative isolates were deposited in the Agricultural Culture Collection of China (ACCC; Beijing, China), and dried cultures were deposited in the Herbarium Mycologicum Academiae Sinicae (HMAS; Beijing, China). New species names and descriptions were deposited in Fungal Names (http://fungalinfo.im.ac.cn/fungalname/fungalname.html).

Culture characteristics and morphological observation. After 2 weeks of growth on PDA and oatmeal agar (OA) plates at $25^{\circ} \mathrm{C}$, colony color was described, and colony diameter was measured. The effect of temperature on mycelial growth on PDA was assessed at temperatures of $5,10,15,20,25,30,35$, and $40^{\circ} \mathrm{C}$. Microscopic examination was carried out after 2 weeks of growth on PDA at $25^{\circ} \mathrm{C}$ in darkness. Isolates were allowed to grow onto an adjacent sterile coverslip that had been partially inserted into the agar surface at a $60^{\circ}$ angle to measure and observe fungal structures ( $\mathrm{Li}$ et al. 2011), and sterile water was used as a mounting medium for microscopy. Wherever possible, measurements were made on 30 spores per isolate (Batzer et al. 2005). 
Genomic DNA extraction, polymerase chain reaction, and sequencing. Genomic DNA for polymerase chain reaction (PCR) was extracted from mycelium that had grown on PDA petri dishes at $25^{\circ} \mathrm{C}$ for 14 days according to the protocol of $\mathrm{Li}$ et al. (2011). Primer pairs ITS1-F/ITS4 (White et al. 1990), LSU1Fd/LR5 (Cubeta et al. 1991; Vilgalys and Hester 1990), ACT-512F/ACT1Rd (Carbone and Kohn 1999; Groenewald et al. 2013), and Tub-F/Tub-R (Cruse et al. 2002) were used to amplify the internal transcribed spacer (ITS) regions 1, 2, and 5.8S rDAN gene, the D1/D2 domains of the large subunit (LSU) nucleus ribosome RNA (nrRNA) gene, a fragment of the actin gene (ACT1), and a fragment of $\beta$-tubulin gene (BT2), respectively. The PCR amplification mixture consisted of 1 unit of Taq polymerase (Thermo Scientific), $1 \times$ Taq buffer, $2 \mathrm{mM} \mathrm{MgCl} 2,0.2 \mathrm{mM}$ dNTPs, $0.4 \mu \mathrm{M}$ forward and reverse primers, and $2 \mu \mathrm{l}$ of template DNA, with sterile water making up the total volume of $25 \mu$ l. Reactions were performed on a PCR System S1000 Thermal Cycler (Bio-Rad). The cycling conditions for ITS and LSU were an initial denaturation at $94^{\circ} \mathrm{C}$ for 3 min followed by 35 cycles of denaturation at $94^{\circ} \mathrm{C}$ for $35 \mathrm{~s}$, annealing at $52^{\circ} \mathrm{C}$ for $60 \mathrm{~s}$, and extension at $72^{\circ} \mathrm{C}$ for $90 \mathrm{~s}$ and a final $10-\mathrm{min}$ extension step at $72^{\circ} \mathrm{C}$. The same cycling conditions were used for amplifying $A C T 1$ and $B T 2$, except that the annealing temperatures were changed to $58^{\circ} \mathrm{C}$ and $63^{\circ} \mathrm{C}$, respectively. The PCR products were sequenced at Organism Technology, Shanghai, China. Sequences were deposited in the National Center for Biotechnology Information's GenBank (Table 1).

Sequence alignment and phylogenetic analysis. Reference sequences used for phylogenetic analysis were downloaded from the
National Center for Biotechnology Information's GenBank sequence database (Table 1). Sequences were aligned with MAFFT v. 7 (http:// mafft.cbrc.jp/alignment/server/index.html), manually inspected, and adjusted using BioEdit v. 5.0.9.1 (Hall 1999) to avoid comparing nonhomologous positions. Maximum parsimony (MP) analysis, maximum likelihood (ML) analysis, and Bayesian analysis were performed with PAUP v. 4.0b 10 (Swofford 2003), RAxML v. 7.0.3 (Stamatakis et al. 2005, 2008), and MrBayes v. 3.1.2 (Altekar et al. 2004), respectively. For MP analysis, heuristic searches were performed with 1,000 random sequence additions. Clade reproducibility was assessed by 1,000 bootstrap replications. For ML analysis, GTRGAMMA was used as the optimal nucleotide substitution model. Clade reproducibility was assessed by 1,000 bootstrap replications. For Bayesian analysis, the optimal nucleotide substitution models for each gene region and the combined data were estimated using MrModeltest v. 2.2 (Nylander 2004). The sequences described in this study were deposited in GenBank. Trees were visualized using TreeView v. 1.6.6 (Page 1996), and alignments and representative trees were deposited in TreeBASE (http://purl.org/ phylo/treebase/phylows/study/TB2:S21591).

Pathogenicity test. Field inoculation. The experiments were performed in an apple orchard located in Yangling, Shaanxi Province, China from June to September 2015. Asymptomatic apple fruit (cv. Fuji), similar in size and lacking blemishes, was selected for inoculation. Fruit surfaces were sanitized with $75 \%$ ethanol for $30 \mathrm{~s}$, rinsed with sterile distilled water, and air dried. A conidial suspension $\left(1 \times 10^{6} \mathrm{ml}^{-1}\right)$ of the test isolates was misted on the surface with

Table 1. Species and GenBank accession numbers included in Acremonium and Sarocladium phylogenetic analyses ${ }^{\mathrm{y}}$

\begin{tabular}{|c|c|c|c|c|c|c|}
\hline \multirow[b]{2}{*}{ Species } & \multirow[b]{2}{*}{ Strain } & \multirow[b]{2}{*}{ Origin } & \multicolumn{4}{|c|}{ GenBank accession number ${ }^{\mathbf{z}}$} \\
\hline & & & LSU/D1D2 & ITS & $A C T 1$ & $\beta$-tubulin \\
\hline Acremonium alternatum & CBS $407.66^{\mathrm{T}}$ & Hypoxylon deustum, Austria & HQ231988 & - & - & - \\
\hline Acremonium borodinense & CBS $101148^{\mathrm{T}}$ & Soil in sugarcane field, Japan & HQ232003 & - & - & - \\
\hline Acremonium brachypenium & CBS $866.73^{\mathrm{T}}$ & Cocos nucifera, Sri Lanka & HQ232004 & - & - & - \\
\hline Acremonium camptosporum & CBS $756.69^{\mathrm{T}}$ & Soil, parasitic on nematodes, Germany & HQ232008 & - & - & - \\
\hline Acremonium cavaraeanum & CBS $101149^{\mathrm{T}}$ & Outer wall of wooden house, Japan & HF680202 & HF680220 & - & HF680240 \\
\hline Acremonium chrysogenum & CBS $144.62^{\mathrm{T}}$ & Soil, Maharashtra & HQ232017 & - & - & - \\
\hline Acremonium citrinum & CBS $384.96^{\mathrm{T}}$ & Decaying fruit, Papua New Guinea & HF680217 & HF680236 & - & HF680257 \\
\hline Acremonium curvulum & CBS $430.66^{\mathrm{T}}$ & Wheat field soil, Germany & HQ232026 & - & - & - \\
\hline Acremonium ехіgиит & CBS $587.73^{\mathrm{T}}$ & $\begin{array}{l}\text { Tubulicium dussii on Dicksonia antarctica, } \\
\text { Sri Lanka }\end{array}$ & HQ232035 & - & - & - \\
\hline Acremonium flavum & CBS $596.70^{\mathrm{T}}$ & Agricultural soil, Germany & HQ232037 & - & - & - \\
\hline Acremonium fusidioides & CBS $840.68^{\mathrm{T}}$ & Dung of antelope, Central African Republic & HQ232039 & FN706542 & & HF680257 \\
\hline Acremonium fusidioides & CBS 266.89 & Agricultural soil, Germany & HF680205 & HF680224 & & HF680245 \\
\hline Acremonium fusidioides & CBS 109069 & Barley seeds, Ethiopia & HF680204 & HF680223 & & HF680244 \\
\hline Acremonium hennebertii & CBS $768.69^{\mathrm{T}}$ & Elaeis guineensis, Zaire & HQ232044 & HF680238 & & HF680260 \\
\hline Acremonium inflatum & CBS $212.69^{\mathrm{T}}$ & $\begin{array}{l}\text { Intertidal salt marsh mud, the United } \\
\text { Kingdom }\end{array}$ & HQ232050 & - & - & - \\
\hline Acremonium mali & ACCC $39305^{\mathrm{T}}$ & Malus $\times$ domestica, China & MF993114 & MF987658 & - & MF987667 \\
\hline Acremonium parvum & CBS $381.70 A^{\mathrm{T}}$ & Tubercularia vulgaris, The Netherlands & HQ231986 & HF680219 & - & HF680239 \\
\hline Acremonium pilosum & CBS $124.70^{\mathrm{T}}$ & Agricultural soil, The Netherlands & HF680209 & HF680228 & - & HF680249 \\
\hline Acremonium pilosum & CBS 410.70 & Agricultural soil, The Netherlands & HF680208 & HF680227 & - & HF680248 \\
\hline Acremonium pilosum & CBS 125.70 & Agricultural soil, The Netherlands & HF680210 & HF680229 & - & HF680250 \\
\hline Acremonium pilosum & CBS 390.73 & Periconia cookie on dead bamboo, India & HQ232043 & AB540578 & - & HF680258 \\
\hline Acremonium persicinum & CBS $310.59^{\mathrm{T}}$ & Tectona grandis, India & HQ232077 & - & - & - \\
\hline Acremonium pinkertoniae & CBS $157.70^{\mathrm{T}}$ & Soil, Italy & HQ232089 & - & - & - \\
\hline Acremonium psammosporum & CBS $590.63^{\mathrm{T}}$ & Bark of Populus canadensis, Belgium & HQ232100 & - & - & - \\
\hline Acremonium pseudozeylanicum & CBS $560.73^{\mathrm{T}}$ & Decaying leaf of Cocos nucifera, Sri Lanka & HQ232101 & - & - & - \\
\hline Acremonium recifei & CBS $137.35^{\mathrm{T}}$ & Mycetoma of human, Brazil & HQ232106 & - & - & - \\
\hline Acremonium roseolum & CBS $289.62^{\mathrm{T}}$ & Dead stems of Dactylis glomerata, Sheffield & HQ232123 & - & - & - \\
\hline Acremonium salmoneum & CBS $721.71^{\mathrm{T}}$ & Dung of deer, Rajasthan & HQ232125 & - & - & - \\
\hline Acremonium sclerotigenum & CBS $124.42^{\mathrm{T}}$ & $\begin{array}{l}\text { Dune sand, under Ammophila and } \\
\text { Convolvulus, France }\end{array}$ & HQ232126 & - & - & - \\
\hline Acremonium sclerotigenum & ACCC 39310 & Malus $\times$ domestica, China & MF987655 & - & - & - \\
\hline & & & & & (Continu & $n$ next page) \\
\hline
\end{tabular}

y ACCC, Agricultural Culture Collection of China, Beijing, China; CBS, CBS-KNAW Fungal Biodiversity Centre, Utrecht, The Netherlands; ET, epitype strain; ITS, internal transcribed spacer; LSU, large subunit; MUCL, Mycothe 'que de l'Universite' Catholique de Louvain, Louvain-la Neuve, Belgium; NT, neotype strain; T, type strain; UTHSC, Fungus Testing Laboratory, University of Texas Health Science Center, San Antonio, Texas.

${ }^{\mathrm{z}}$ Accession numbers of sequences newly determined in this study are indicated in bold. 
a handheld spray bottle until runoff. Fruit bags were used to enclose fruit after the conidial suspension was almost air dry. For the control, sterile water was used instead of a conidial suspension. Lesion symptoms were assessed at 30 days after inoculation, when spots were $>1 \mathrm{~mm}$ in diameter, and when reisolations were done. Four fruits were inoculated for each treatment. The experiment was performed three times on different dates (25 June, 10 August, and 12 September).

In vitro inoculation. Healthy mature apple fruits (cv. Fuji) purchased from a local grocery store were used for laboratory detached fruit inoculation in Yangling, Shaanxi. The fruits were washed with sterile water and surface disinfected with $75 \%$ ethyl alcohol for $30 \mathrm{~s}$; then, they were rinsed with sterile distilled water. After the surface had air dried, a sterile inoculating needle was used to make about 30 wounds $(0.3-\mathrm{mm}$ deep and $0.3 \mathrm{~mm}$ in diameter) on the surface, after which conidial suspensions $\left(1 \times 10^{6} \mathrm{ml}^{-1}\right)$ of test isolates ACCC 39311, ACCC 39305, ACCC 39306, ACCC 39309, and ACCC 39308 were misted on the fruit surface until runoff. For the control, sterile water was used instead of a conidial suspension. For each isolate, four fruits were inoculated. Inoculated fruits were transported to a moisture chamber with $100 \% \mathrm{RH}$ at $25^{\circ} \mathrm{C}$. Ten days after inoculation, symptom development was assessed. The experiment was conducted three times on different dates. Ten days after inoculation, when lesions surrounding the inoculation site were $>1 \mathrm{~mm}$ in diameter, reisolations of the causal agent were attempted, and the ITS regions of these isolates were PCR amplified and sequenced.

Effects of temperature and RH on conidial germination. The effect of temperature on conidial germination was tested at 5, 10,
$15,20,25,30,35$, and $40^{\circ} \mathrm{C}$ in distilled water. After a droplet $(10 \mu \mathrm{l})$ of conidia suspension $\left(1 \times 10^{6} \mathrm{ml}^{-1}\right)$ was placed at each end of a sterile glass slide with a micropipette, the slide was placed in a 9-cm-diameter petri dish sealed with Parafilm containing $30 \mathrm{ml}$ of $2 \%$ water agar to maintain the moisture of conidia suspension. The effect of RH was tested at RHs of $100,99,97$, and $95 \%$ as well as a distilled water control. A droplet $(10 \mu \mathrm{l})$ of conidial suspension $\left(1 \times 10^{6} \mathrm{ml}^{-1}\right)$ was placed at each end of a slide and air dried, after which the slide was placed inside a 9-cm-diameter petri dish containing $30 \mathrm{ml} 2 \%$ water agar amended with different amounts of $\mathrm{NaCl}$. The petri dish was sealed with Parafilm. RH levels of $100,99,97$, and $95 \%$ were achieved with $0,0.3,0.9$, or $1.5 \mathrm{M} \mathrm{NaCl}$, respectively (Harris et al. 1970; Lang 1967; Wang et al. 2015). The petri dishes were placed in incubators at $25^{\circ} \mathrm{C}$. The experiment was performed four times.

After 12 or $16 \mathrm{~h}$ of inoculation, a drop $(10 \mu \mathrm{l})$ of lactophenol (lactic acid/phenol/glycerin/distilled water $=1: 1: 2: 1[\mathrm{vol} / \mathrm{vol} / \mathrm{vol} / \mathrm{vol}])$ was added to each conidia suspension droplet to stop germination (Wang et al. 2015). Percentage conidial germination was measured by observing 500 conidia wherever possible with microscopy (Olympus BX51); conidia were considered to be germinated when the germ tube was longer than one-half the total length of a conidium.

Effects of temperature and RH on infection. The effects of temperature on infection by $A$. sclerotigenum were examined at seven temperature levels $\left(10,15,20,25,30,35\right.$, and $\left.40^{\circ} \mathrm{C}\right)$. The inoculation method was the same as in the in vitro trials with wound inoculation

Table 1. (Continued from previous page)

\begin{tabular}{|c|c|c|c|c|c|c|}
\hline \multirow[b]{2}{*}{ Species } & \multirow[b]{2}{*}{ Strain } & \multirow[b]{2}{*}{ Origin } & \multicolumn{4}{|c|}{ GenBank accession number ${ }^{\mathrm{z}}$} \\
\hline & & & LSU/D1D2 & ITS & $A C T 1$ & $\beta$-tubulin \\
\hline Acremonium sclerotigenum & ACCC 39311 & Malus $\times$ domestica, China & MF987656 & - & - & - \\
\hline Acremonium sclerotigenum & ACCC 39312 & Malus $\times$ domestica, China & MF987657 & - & - & - \\
\hline Acremonium spinosum & CBS $136.33^{\mathrm{T}}$ & Toe nail of man, Argentina & HQ232137 & - & - & - \\
\hline Acremonium tubakii & CBS $790.69^{\mathrm{T}}$ & Marine sediment, Japan & HQ232148 & - & - & - \\
\hline Cosmospora khandalensis & CBS $356.65^{\mathrm{T}}$ & $\begin{array}{l}\text { Decaying stem of the genus Bambusa, } \\
\text { Maharashtra }\end{array}$ & HQ231996 & - & - & - \\
\hline Cosmospora lavitskiae & CBS $530.68^{\mathrm{T}}$ & $\begin{array}{l}\text { Plant debris from rhizosphere soil of Zea } \\
\text { mays, Ukraine }\end{array}$ & HQ231997 & - & - & - \\
\hline Gliomastix masseei & CBS 794.69 & Morus indica, Punjab & HQ232060 & - & - & - \\
\hline Gliomastix murorum & CBS 157.72 & $\begin{array}{l}\text { Culture of Camarophyllus niveus, The } \\
\text { Netherlands }\end{array}$ & HQ232067 & - & - & - \\
\hline Gliomastix polychroma & CBS $181.27^{\mathrm{T}}$ & Bark of Hevea brasiliensis, Sumatra & HQ232091 & - & - & - \\
\hline Sarocladium bacillisporum & CBS $425.67^{\mathrm{T}}$ & Soil, Ontario, Canada & HE608658 & HE608639 & HE608633 & - \\
\hline Sarocladium bactrocephalum & CBS $749.69^{\mathrm{T}}$ & Ustilago sp., Canada & HQ231994 & HG965006 & HG964952 & - \\
\hline Sarocladium bactrocephalum & UTHSC 09-384 & Human eye, U.S.A. & HG965055 & HG965007 & HG964957 & - \\
\hline Sarocladium bifurcatum & UTHSC $05-3311^{\mathrm{T}}$ & Bronchoalveolar lavage fluid, U.S.A. & HG965057 & HG965009 & HG964959 & - \\
\hline Sarocladium gamsii & CBS $707.73^{\mathrm{T}}$ & Dead stem of Pandanus lerum, Sri Lanka & HG965063 & HG965015 & HG964965 & - \\
\hline Sarocladium glaucum & CBS $796.69^{\mathrm{T}}$ & Woolen overcoat, Solomon Islands & HE608657 & FN691454 & HE608631 & - \\
\hline Sarocladium hominis & UTHSC 04-1034 & Right calf tissue, U.S.A. & HG965060 & HG965012 & HG964962 & - \\
\hline Sarocladium implicatum & CBS $959.73^{\mathrm{NT}}$ & Desert soil, Egypt & HG965072 & HG965023 & HG964974 & - \\
\hline Sarocladium kiliense & CBS $122.29^{\mathrm{T}}$ & Skin, Germany & HQ232052 & FN691446 & HG964975 & - \\
\hline Sarocladium liquanensis & ACCC $39306^{\mathrm{T}}$ & Malus $\times$ domestica, China & MF987651 & MF987659 & MF987663 & - \\
\hline Sarocladium mali & ACCC $39308^{\mathrm{T}}$ & Malus $\times$ domestica, China & MF987653 & MF987662 & MF987665 & - \\
\hline Sarocladium mali & ACCC 39307 & Malus $\times$ domestica, China & MF987652 & MF987661 & MF987664 & - \\
\hline Sarocladium ochraceum & CBS $428.67^{\mathrm{T}}$ & Zea mays, Kenya & HQ232070 & HG965025 & HG964977 & - \\
\hline Sarocladium oryzae & CBS $180.74^{\mathrm{ET}}$ & Oryza sativa, India & HG965047 & HG965026 & HG964978 & - \\
\hline Sarocladium pseudostrictum & UTHSC 02-1892 & Sputum, U.S.A. & HG965073 & HG965029 & HG964981 & - \\
\hline Sarocladium strictum & CBS $346.70^{\mathrm{T}}$ & Triticum aestivum, Germany & HQ232141 & FN691453 & HG964982 & - \\
\hline Sarocladium strictum & CBS 640.75 & Decaying wood, The Netherlands & HG965074 & HG965030 & HG964983 & - \\
\hline Sarocladium subulatum & MUCL $9939^{\mathrm{T}}$ & Soil, Egypt & HG965075 & HG965031 & HG964984 & - \\
\hline Sarocladium summerbellii & CBS $430.70^{\mathrm{T}}$ & Soil from greenhouse, The Netherlands & HG965078 & HG965034 & HG964987 & - \\
\hline Sarocladium terricola & CBS $243.59^{\mathrm{T}}$ & Forest soil, U.S.A. & HE608659 & FN706553 & HE608632 & - \\
\hline Sarocladium terricola & MUCL 12011 & $\begin{array}{l}\text { Decaying leaf of Milleta laurentii, } \\
\text { Democratic Republic of Congo }\end{array}$ & HG965083 & HG965039 & HG964991 & - \\
\hline Sarocladium terricola & UTHSC 03-2933 & Bronchial wash fluid, U.S.A. & HG965086 & HG965041 & HG964994 & - \\
\hline Sarocladium terricola & ACCC 39309 & Malus $\times$ domestica, China & MF987654 & MF987660 & MF987666 & - \\
\hline Sarocladium zeae & CBS $800.69^{\mathrm{T}}$ & Zea mays stalk, U.S.A. & HQ232152 & FN691451 & HG965000 & - \\
\hline
\end{tabular}


as described above. After inoculation, the apples were placed in sealed plastic bags, sterile water was misted on the inside surface of the plastic bags until runoff to maintain high $\mathrm{RH}$, and bags containing inoculated fruit were placed in incubators at different temperatures. RH was controlled by saturated salt solution. Pure water, saturated potassium sulfate, potassium nitrate, potassium chloride, and sodium chloride solutions were placed in sealed glass jars to maintain $\mathrm{RH}$ at $100,98,95,85$, or $75 \%$, respectively (Rockland
1960). Inoculated and control fruits used for RH experiments were air dried and then, transported to moist air cabinets with different $\mathrm{RH}$ levels. The experiment was performed four times, and four fruits were used per treatment. Symptom development was assessed 10 days after inoculation.

Data analysis. Conidial germination percentages obtained in four experiments performed on different dates were used to calculate treatment means and standard errors. Analysis of variance was
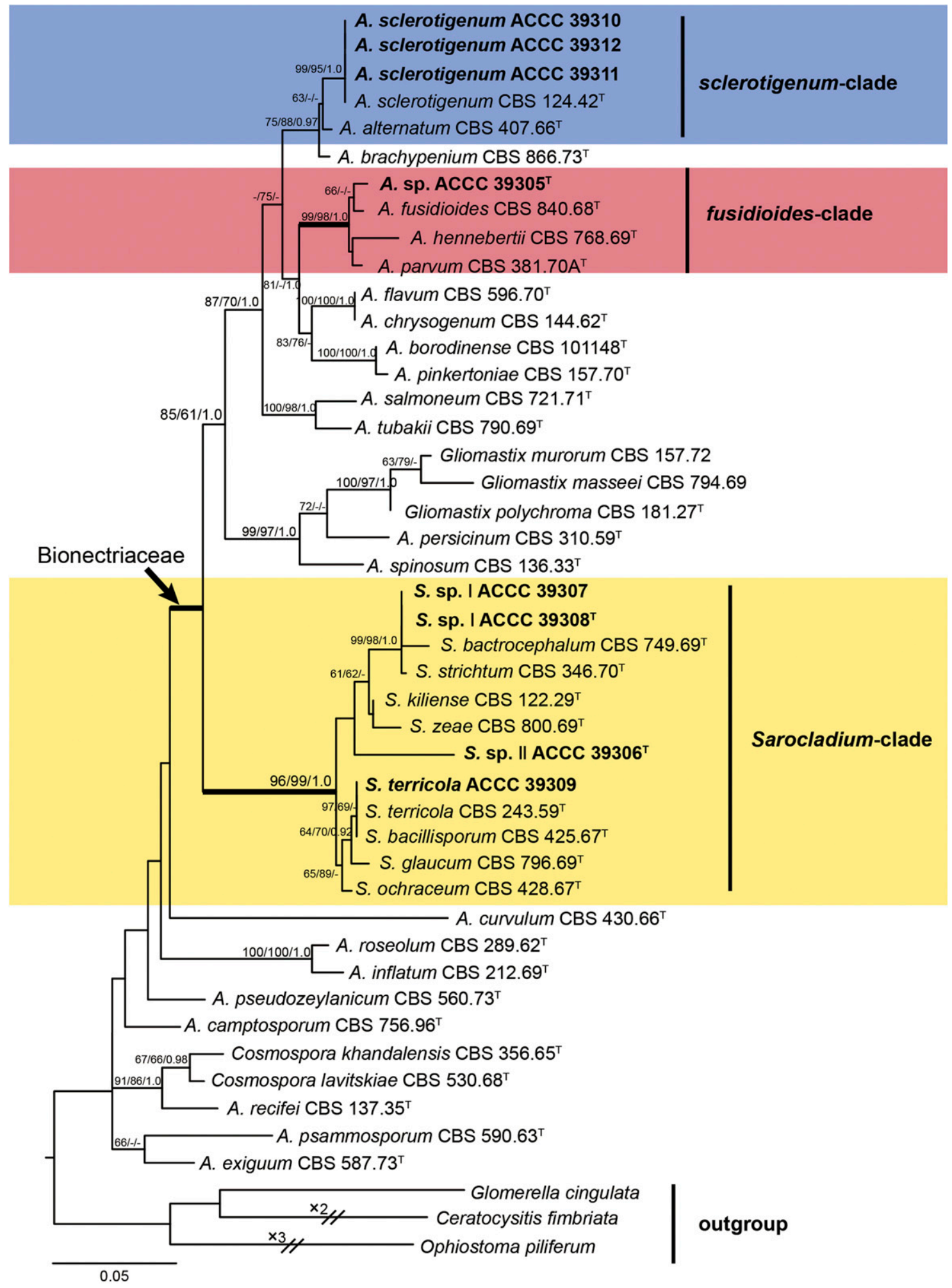

Fig. 1. The most likely tree based on LSU sequences. Maximum likelihood bootstrap (MLBS) $>60 \%$, maximum parsimony bootstrap (MPBS) $>60 \%$, and Bayesian posterior probabilities (BPP) $>0.90$ are given at the nodes. The scale bar represents the number of nucleotide substitutions per site. The tree is rooted to Ceratocystis fimbriata, Ophiostoma piluliferum, and Glomerella cingulata. Strains generated in this study are shown in bold, and the type strains are indicated by superscript T. 


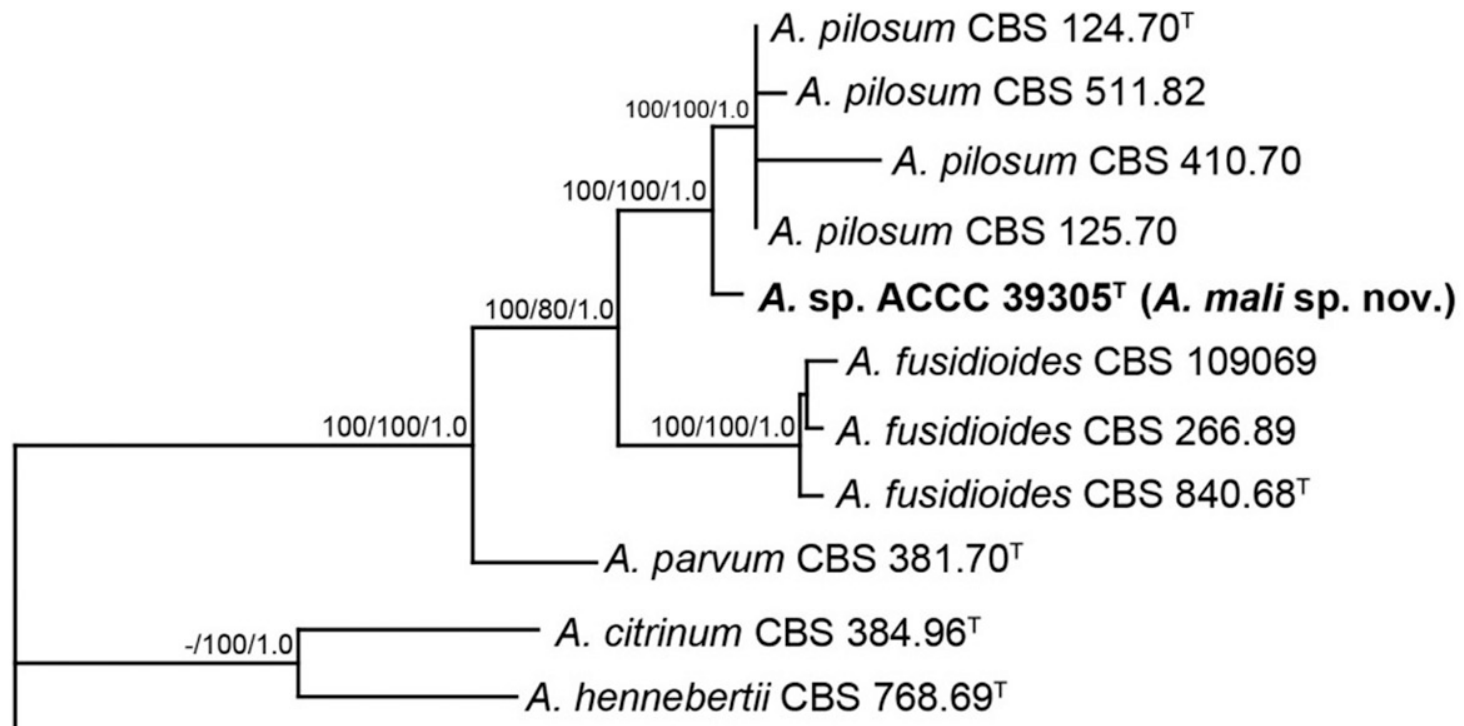

A. cavaraeanum CBS $101149^{\top}$

10

Fig. 2. One of most parsimonious trees based on the combined dataset of LSU-ITS-BT2. Maximum likelihood bootstrap (MLBS) $>60 \%$, maximum parsimony bootstrap (MPBS) $>60 \%$, and Bayesian posterior probabilities (BPP) $>0.90$ are given at the nodes. The scale bar represents the expected changes per site. The tree is rooted to Acremonium cavaraeanum. Strains generated in this study are shown in bold, and the type strains are indicated by superscript T.

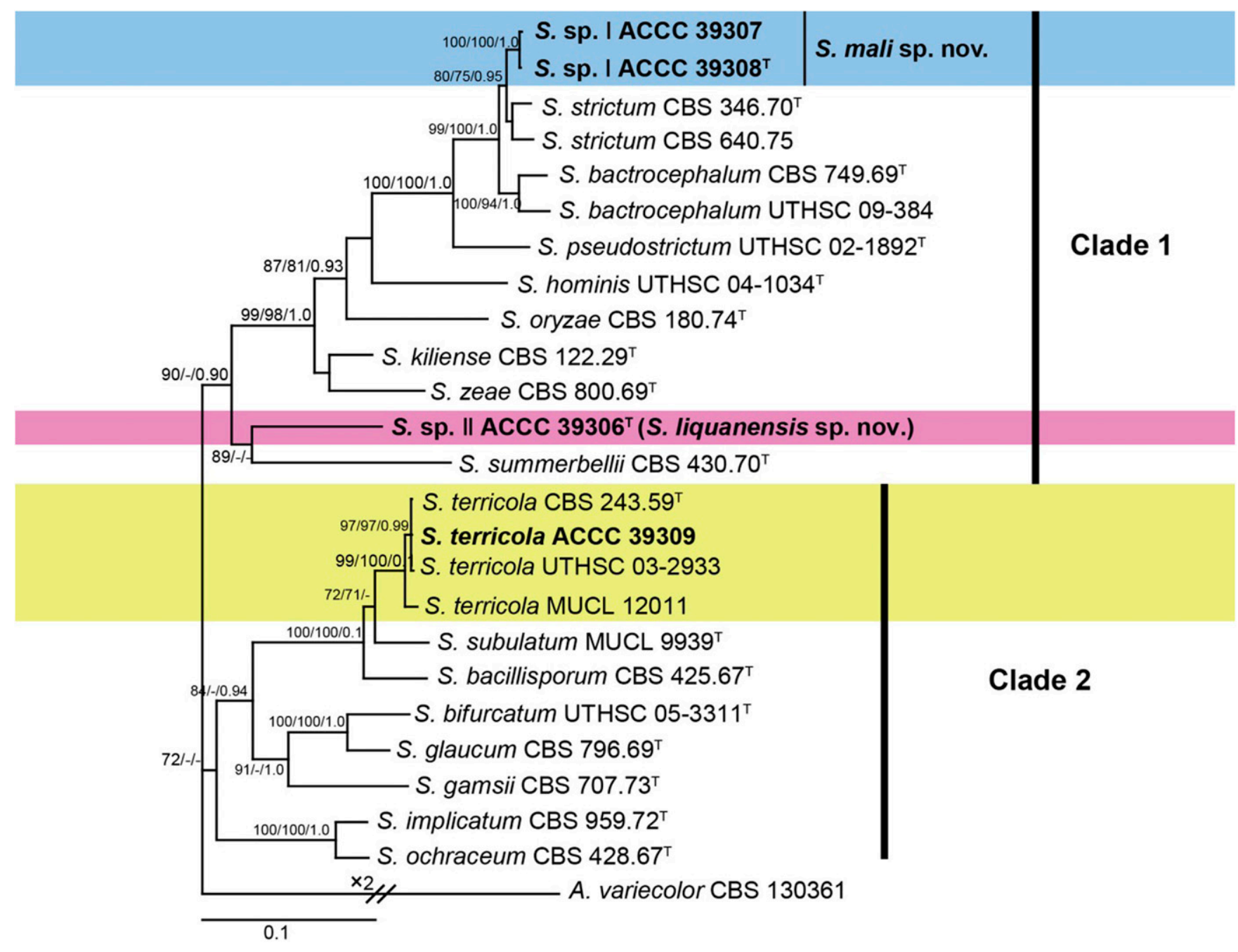

Fig. 3. Consensus phylogram resulting from a Bayesian analysis of the LSU-ITS-ACT1 dataset of the genus Serocladium. Maximum likelihood bootstrap (MLBS) $>60 \%$, maximum parsimony bootstrap (MPBS) $>60 \%$, and Bayesian posterior probabilities (BPP) $>0.90$ are given at the nodes. The scale bar represents the expected changes per site. The tree is rooted to Acremonium variecolor. Strains generated in this study are shown in bold, and the type strains are indicated by superscript T. 

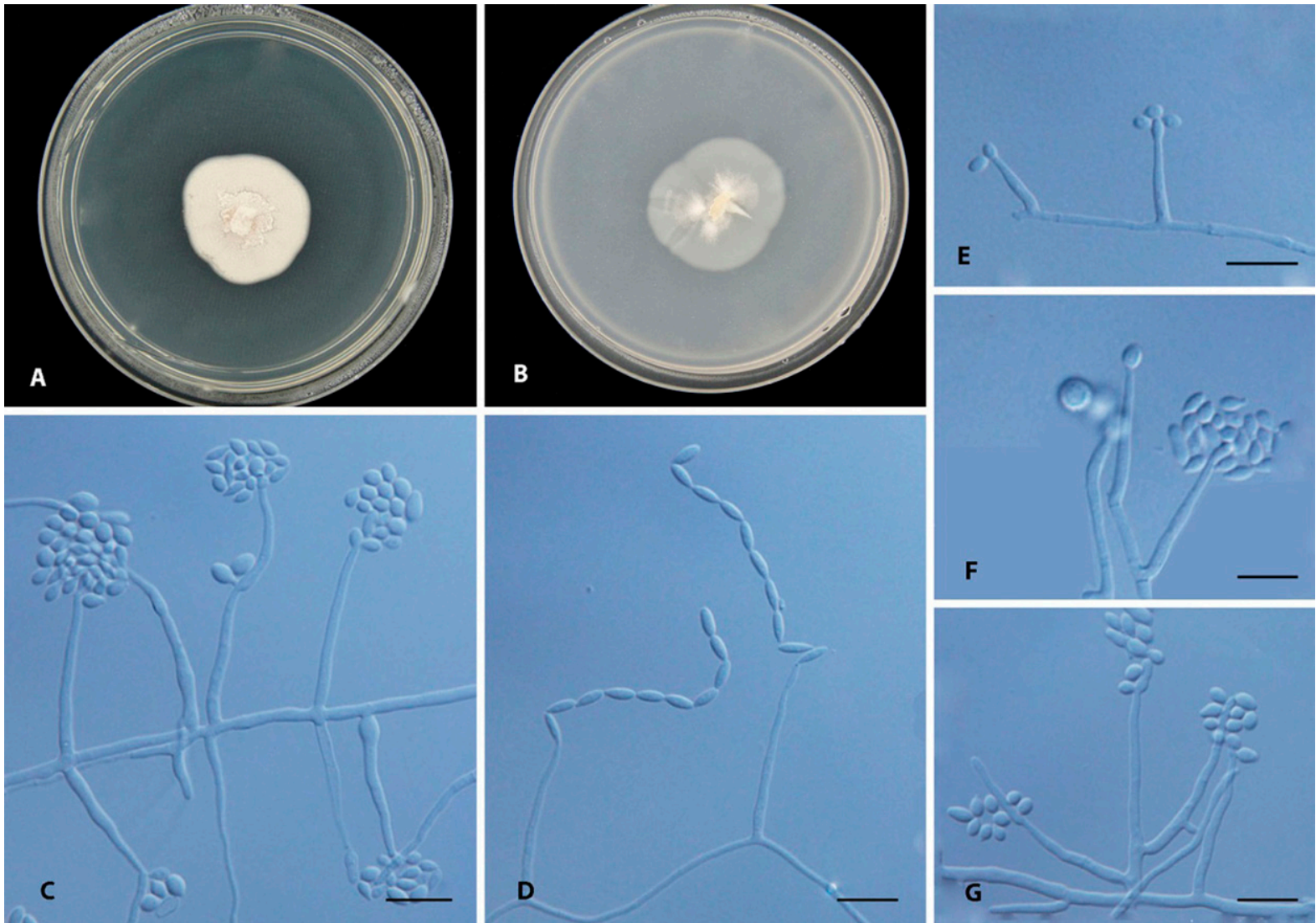

Fig. 4. Acremonium mali (strain ACCC 39305 (stored in Agricultural Culture Collection of China). A and B, Colonies on potato dextrose agar and oatmeal agar, respectively, after 14 days at $25^{\circ} \mathrm{C}$. $\mathbf{C}$ and $\mathbf{D}$, Conidia gathered in slimy head and long chain, respectively. E, Adelophialides. F, Globose conidia. G, Branched conidiophores. Scale bars $=10 \mu \mathrm{m}$.
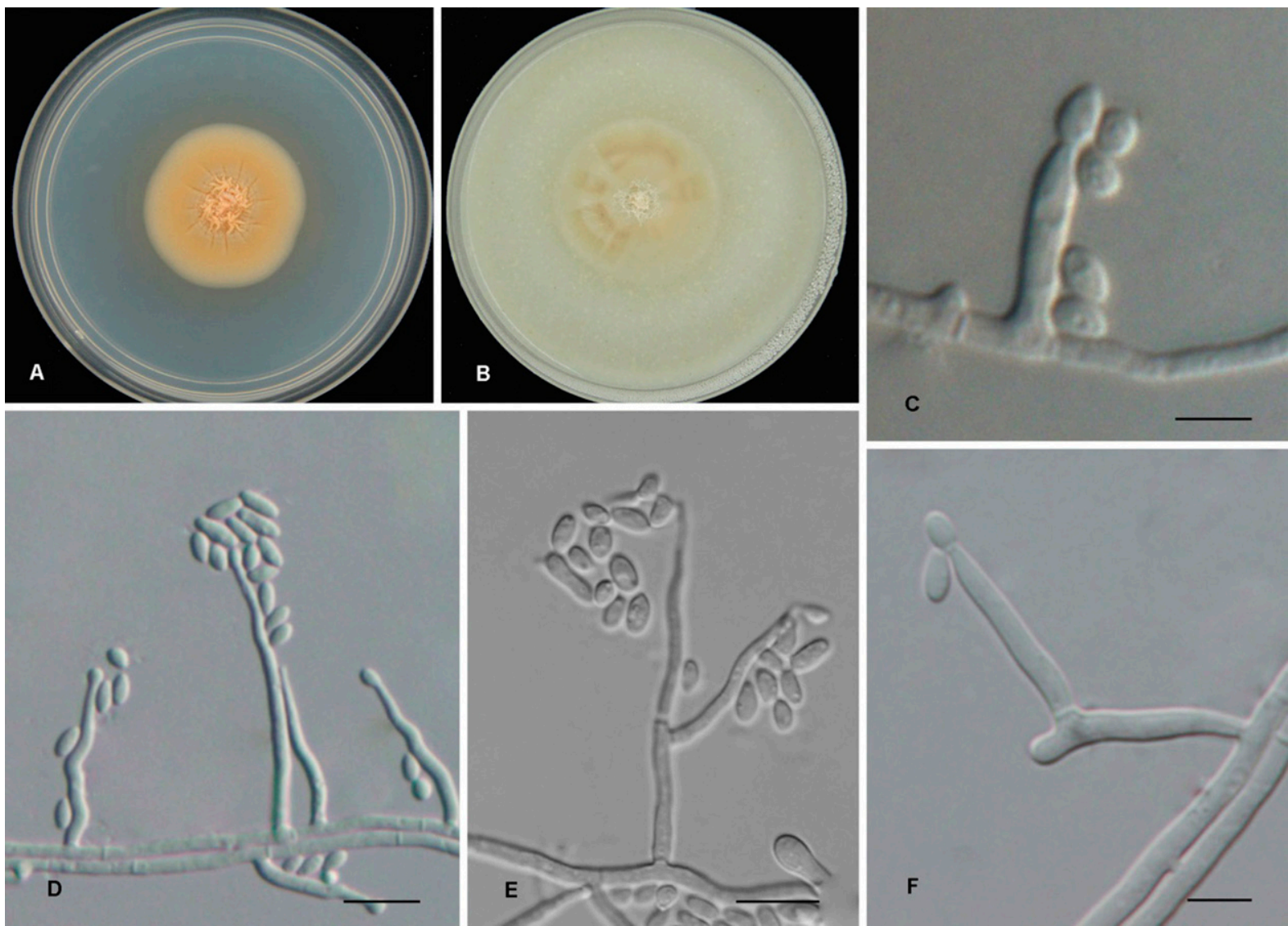

Fig. 5. Sarocladium liquanensis (strain ACCC 39306 (stored in Agricultural Culture Collection of China). A and B, Colonies on potato dextrose agar and oatmeal agar, respectively, after 14 days at $25^{\circ} \mathrm{C}$. C, Adelophialides. D, Conidia gathered in slimy head. E and F, Branched conidiophores. Scale bars $=10 \mu \mathrm{m}$. 
conducted using generalized line models to assess the effects of temperature and $\mathrm{RH}$ on conidial germination.

\section{Results}

Phylogenetic analysis. In total, 60 fungal isolates that were similar to the genus Acremonium in morphology were isolated from apple brown spot lesions. Eight representative isolates were chosen for additional phylogenetic analysis with LSU markers (Table 1). The LSU dataset, including 38 reference species in Hypocreales, resulted in an alignment with 700 characters. Phylogenetic trees constructed with MP, ML, and Bayesian analyses were highly congruent (Fig. 1). The eight isolates fell into three clades (Sclerotigenum clade, Fusidioides clade, and Sarocladium clade) in Bionectriaceae (Summerbell et al. 2011). The Sclerotigenum clade contained three isolates (ACCC 39312, ACCC 39311, and ACCC 39310) that were phylogenetically indistinguishable from A. sclerotigenum type strain CBS 124.42. Based on morphological and phylogenetic characteristics, these isolates were identified as A. sclerotigenum.

The Fusidioides clade contained one isolate, ACCC 39305. An LSU-ITS-BT2 multigene phylogenetic analysis was performed to determine its phylogenetic position (Fig. 2). A total of 11 reference sequences were included in the alignment, which contained 1,545 characters (476/500/570 bp of LSU/ITS/BT2). The topologies of three methods were consistent, and isolate ACCC 39305 clustered together with Acremonium fusidioides and Acremonium pilosum with support of 100\% maximum likelihood bootstrap (MLBS), 100\% maximum parsimony bootstrap (MPBS), and 1.00 Bayesian posterior probabilities (BPP). Isolate ACCC 39305 formed an independent clade with $100 \%$ MLBS, $100 \%$ MPBS, and 1.00 BPP. All species in the Fusidioides clade can produce two kinds of conidia (Giraldo et al. 2014).
The Sarocladium clade contained four isolates: ACCC 39306, ACCC 39307, ACCC 39308, and ACCC 39309. An LSU-ITSACT1 multigene phylogenetic analysis was performed to determine their phylogenetic positions (Fig. 3). A total of 21 taxa were aligned in the genus Sarocladium, including one outgroup taxon, which contained 1,755 characters (505/520/730 bp of LSU/ITS/ACT1). The Sarocladium isolates formed two well-supported clades, with clade 1 producing conidia in chains and clade 2 producing conidia in slimy heads, except for Sarocladium gamsii (in clade 1) and Sarocladium summerbellii (in clade 2), which can produce conidia in both chains and slimy heads (Giraldo et al. 2015). Isolates ACCC 39307, ACCC 39308, and ACCC 39306 produced conidia in slimy heads and belonged to clade 1. Isolates ACCC 39307 and ACCC 39308 separated with Sarocladium strictum with strong support (80\% MLBS, 75\% MPBS, and $0.95 \mathrm{BPP}$ ). Isolate ACCC 39306 formed an independent clade. In clade 2, the isolate ACCC 39309 was indistinguishable from the type strain of Sarocladium terricola CBS 243.59.

Taxonomy. Based on the morphological and molecular data, the brown spot complex includes three new species.

Acremonium mali G. Y. Sun \& Yanmin Hou, sp. nov. (Fig. 4): FN570590. Etymology. It was named after the host (Malus $\times$ domestica) from which it was collected.

Holotype. China, Shaanxi Province: Xianyang City, on Malus $\times$ domestica Borkh., October 2013, Yanmin Hou, HMAS247717 (dried culture), ex type ACCC (Agricultural Culture Collection of China) 39305.

Colonies on $\mathrm{OA}$ at $25^{\circ} \mathrm{C}$ attained $44 \mathrm{~mm}$ in 14 days: white, flat, and membranous. On PDA at $25^{\circ} \mathrm{C}$, they attained $43 \mathrm{~mm}$ in 14 days: white, flat, and powdery. Vegetative hyphae septate, hyaline, smooth and thin walled: (1.21) 1.53 to 2.67 (2.81)- $\mu \mathrm{m}$ wide. Conidiophores erect, usually simple, sometimes branched, straight or slightly bent
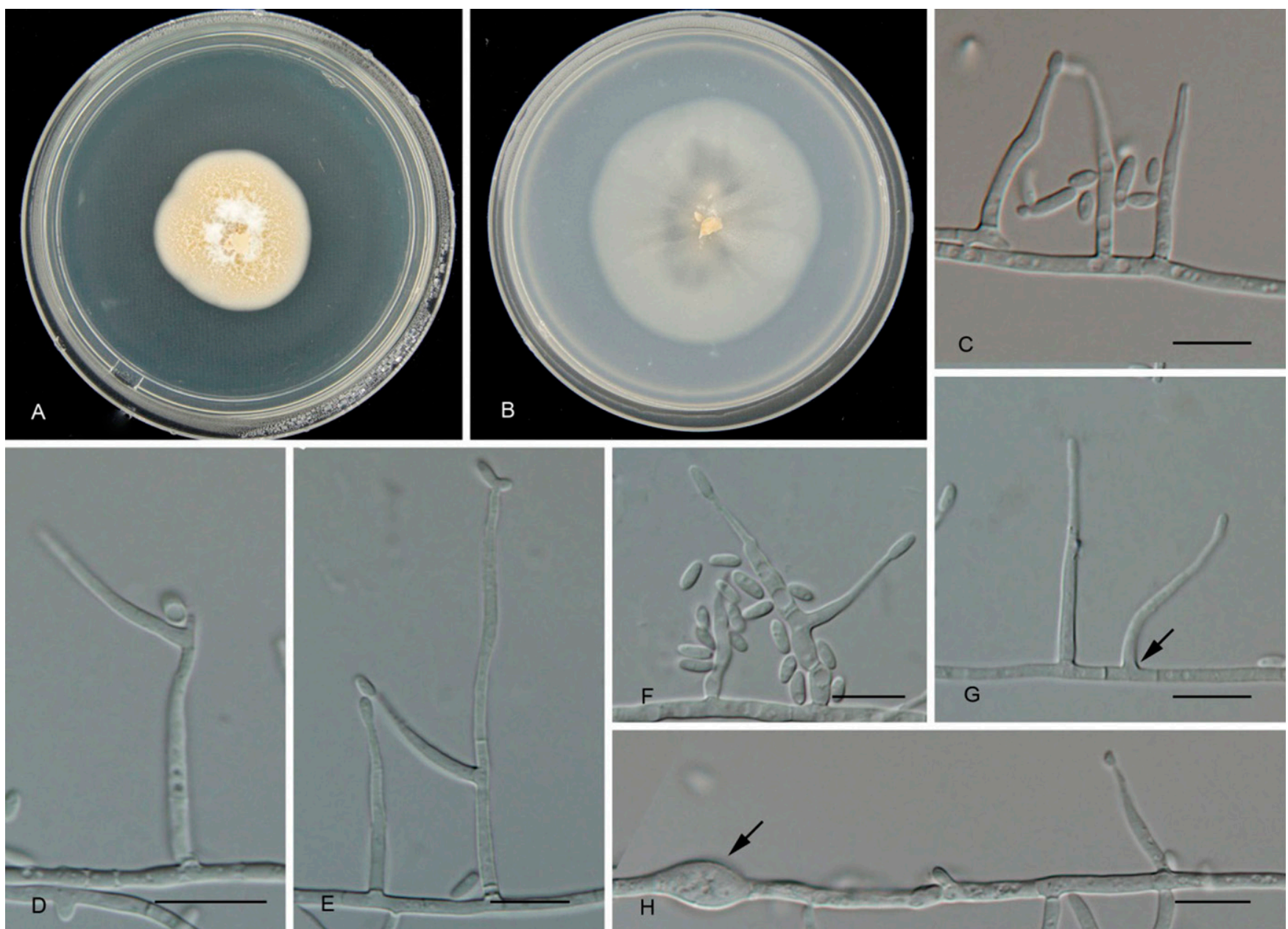

Fig. 6. Sarocladium mali (strain ACCC 39308, stored in Agricultural Culture Collection of China). A and B, Colonies on potato dextrose agar and oatmeal agar, respectively, after 14 days at $25^{\circ} \mathrm{C}$. C and F, Conidia gathered in slimy head. D, Schizophialides. E, Branched conidiophores. G, Adelophialides. H, Chlamydospores. Scale bars $=10 \mu \mathrm{m}$. 
up to (7.80) 10.13 to 26.16 (35.23)- $\mu \mathrm{m}$ long, hyaline, smooth walled. Phialides subulate, (8.51) 9.63 to 21.36 (22.77)- $\mu \mathrm{m}$ long, (1.56) 1.61 to 2.21 (2.76)- $\mu \mathrm{m}$ wide at the base, hyaline, thin and smooth walled; adelophialides present, and schizophialides not observed. Conidia unicellular of two types. I. Pyriform or fusiform with slightly truncate ends, (3.19) 3.66 to $5.46(6.55) \times(1.76)$ 1.92 to 2.48 (3.14) $\mu \mathrm{m}$, hyaline, thin and smooth walled, adhering in long chains or slimy heads. II. Globose with warty surface, hyaline, arranged in chains. Chlamydospores and sexual morph were not observed.

Cardinal temperature for growth. Optimum 20 to $25^{\circ} \mathrm{C}$, maximum $35^{\circ} \mathrm{C}$, and minimum $15^{\circ} \mathrm{C}$. No growth at $37^{\circ} \mathrm{C}$.

Notes. In ML, MP, and Bayes trees, A. mali separated from A. pilosum with support values of 100/100/1.0. These species were distinguishable in both colony and conidia characters. The colony of A. mali was white, whereas A. pilosum was grayish brown at the center with whitish periphery. The former can grow at $35^{\circ} \mathrm{C}$, whereas the latter cannot. Both species produce two types of conidia. The globose conidia produced by A. pilosum were pale brown with filiform projections, whereas those produced by $A$. mali were hyaline and smooth.

Sarocladium liquanensis G. Y. Sun \& Yanmin Hou, sp. nov. (Fig. 5): FN570587. Etymology. It refers to the place (Liquan County, Shaanxi Province) where it was discovered.

Holotype. China, Shanxi Province: Xianyang City, Liquan County, on Malus $\times$ domestica Borkh., October 2013, Yanmin Hou, HMAS247718 (dried culture), ex type ACCC 39306.

Colonies on $\mathrm{OA}$ at $25^{\circ} \mathrm{C}$ attained $44 \mathrm{~mm}$ in 14 days: light orange, flat, and usually fasciculate at the center and glabrous toward the periphery. On PDA at $25^{\circ} \mathrm{C}$, they attained $43 \mathrm{~mm}$ in 14 days: orange,
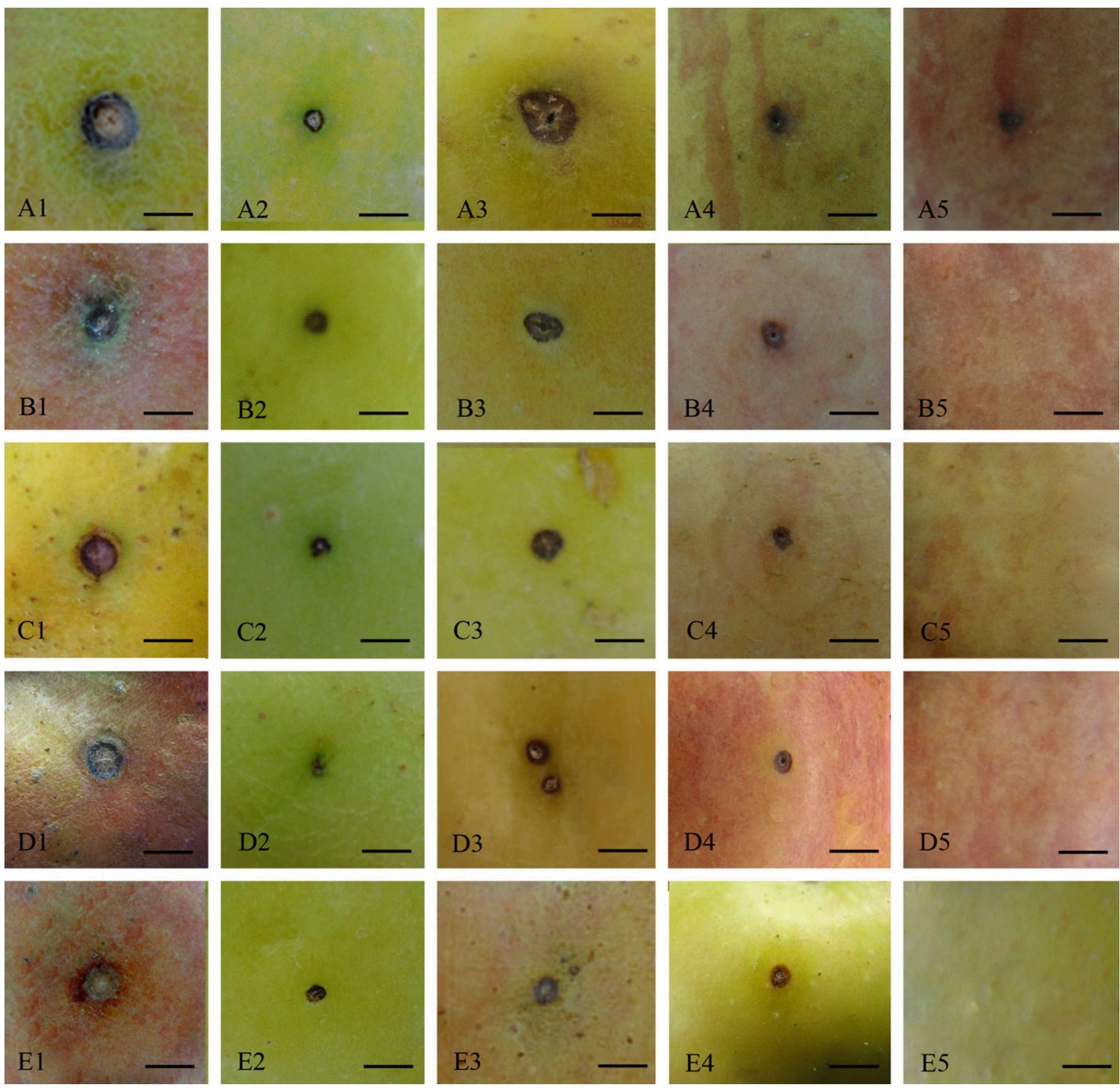

Fig. 7. Symptoms on apple fruit. A, Acremonium sclerotigenum ACCC 39311 (stored in Agricultural Culture Collection of China). B, Acremonium mali ACCC 39305 . C, Sarocladium liquanensis ACCC 39306. D, Sarocladium terricola ACCC 39309. E, Sarocladium mali ACCC 39308. A1, B1, C1, D1, and E1, Symptoms on samples from field. A2, B2, C2, D2, and E2, Symptoms on field fruit inoculated on 25 June. A3, B3, C3, D3, and E3, Symptoms on field fruit inoculated on 10 August. A4, B4, C4, D4, and E4, Symptoms inoculated on detached fruit in laboratory with wounds. A5, B5, C5, D5, and E5, Symptoms inoculated on detached fruit in laboratory with no wound. Scale bars $=5 \mathrm{~mm}$. 
slightly wrinkled or cerebriform in the center, and producing red orange pigment at $30^{\circ} \mathrm{C}$. Vegetative hyphae septate, hyaline, smooth and thin walled, (1.10) 1.33 to 2.58 (2.71)- $\mu \mathrm{m}$ wide. Conidiophores erect, usually simple or branched, straight or slightly bent, up to (8.82) 10.03 to 27.16 (34.26)- $\mu \mathrm{m}$ long, hyaline, smooth walled. Phialides subulate, (8.91) 9.62 to 20.38 (21.07)- $\mu \mathrm{m}$ long, (1.48)

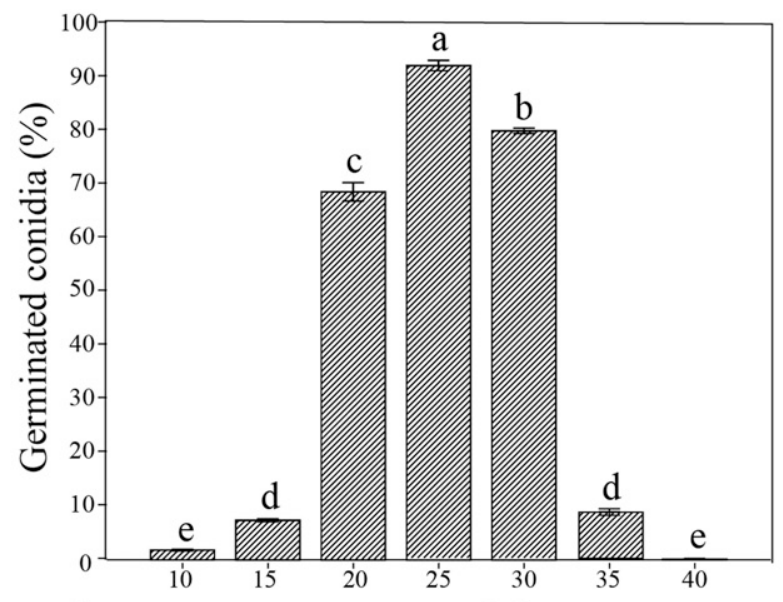

A $\quad$ Temperature $\left({ }^{\circ} \mathrm{C}\right)$
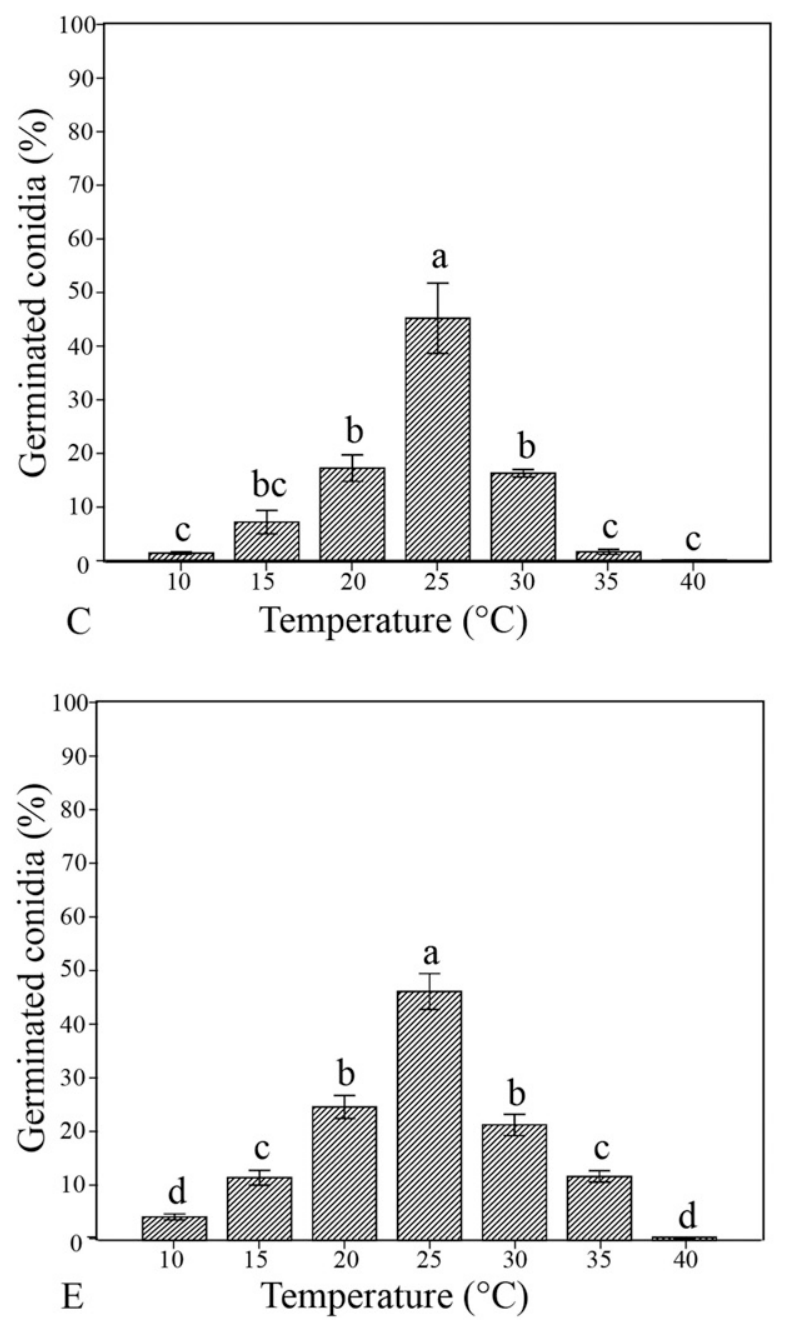

1.51 to 2.31 (2.36)- $\mu \mathrm{m}$ wide at the base, hyaline, thin and smooth walled; adelophialides present, and schizophialides not observed. Conidia unicellular, ellipsoidal to cylindrical, (3.19) 3.66 to 5.46 $(6.55) \times(1.76) 1.92$ to 2.48 (3.14) $\mu \mathrm{m}$, initially hyaline and smooth walled, arranged in slimy heads. Chlamydospores was present, and sexual morph was not observed.
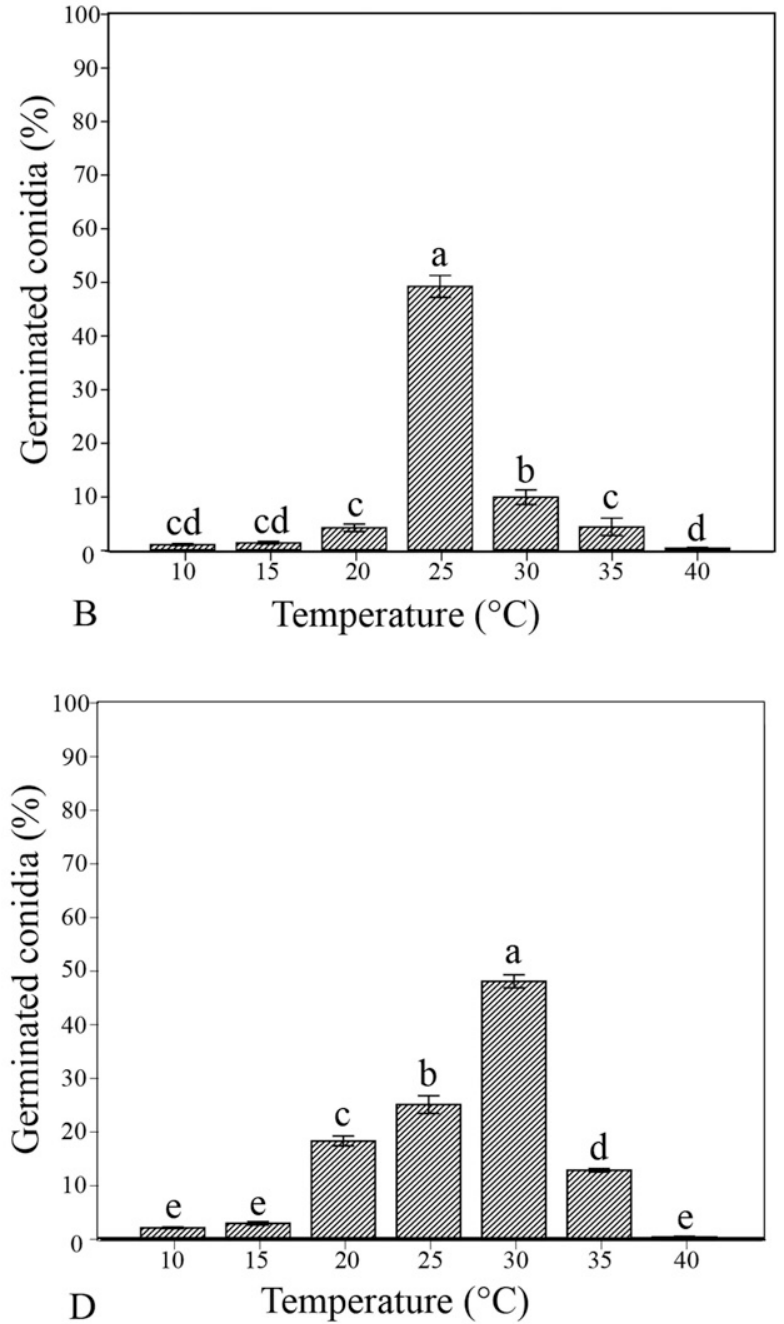

Fig. 8. Effect of temperature on conidial germination. The average germination rate and the corresponding standard error (calculated based on the data in Table 2) at each temperature in the free water treatment are shown as a bar and a corresponding error bar, respectively. Different letters indicate that the germination rates were significantly different $(P<0.05)$ according to multiple comparisons of predicted values by the generalized linear model. A, Acremonium sclerotigenum ACCC 39311 (stored in Agricultural Culture Collection of China). B, Acremonium mali ACCC 39305. C, Sarocladium liquanensis ACCC 39306. D, Sarocladium terricola ACCC 39309. E, Sarocladium mali ACCC 39308. 
Cardinal temperature for growth. Optimum 20 to $25^{\circ} \mathrm{C}$, maximum $35^{\circ} \mathrm{C}$, and minimum $15^{\circ} \mathrm{C}$. No growth at $37^{\circ} \mathrm{C}$.

Notes. In ML, MP, and Bayes trees, the new species gathered with the second large clade, which can produce conidia in slimy heads. In this clade, apart from $S$. summerbellii, which produces fusiform conidia in both chains and slimy heads, all other species produce ellipsoidal or cylindrical conidia. The new species can be distinguished from other species by producing orange pigment when cultivated at $30^{\circ} \mathrm{C}$.

Sarocladium mali G. Y. Sun \& Yanmin Hou, sp. nov. (Fig. 6): FN570588. Etymology. It is named after the host (Malus $\times$ domestica) from which it was collected.

Holotype. China, Shanxi Province: Yangling, on Malus $\times$ domestica Borkh., October 2013, Yanmin Hou, HMAS247719 (dried culture), ex type ACCC 39308.

Colonies on $\mathrm{OA}$ at $25^{\circ} \mathrm{C}$ attained 50 to $60 \mathrm{~mm}$ in 14 days: orange white and membranous. On PDA at $25^{\circ} \mathrm{C}$, they attained $45 \mathrm{~mm}$ in 14 days: light orange, at first membranous, and then becoming powdery. Vegetative hyphae septate, hyaline, smooth and thin walled, (1.16) 1.22 to $2.51-\mu \mathrm{m}$ wide. Conidiophores erect, simple or branched, straight or slightly bent, up to (11.16) 14.67 to 27.73 (31.30)- $\mu \mathrm{m}$ long, hyaline, smooth walled. Phialides subulate, (11.62) 14.56 to 24.74 (31.50)- $\mu \mathrm{m}$ long, (1.32) 1.40 to 1.96 (2.13)- $\mu \mathrm{m}$ wide at the base, hyaline, thin and smooth walled; adelophialides and schizophialides are present. Conidia unicellular, ellipsoidal to cylindrical, (4.03) 4.08 to $4.44(5.19) \times(1.43) 1.54$ to $2.04 \mu \mathrm{m}$, initially hyaline and smooth walled, arranged in slimy heads. Chlamydospores are present, and sexual morph was not observed.

Cardinal temperature for growth. Optimum 20 to $25^{\circ} \mathrm{C}$, maximum $35^{\circ} \mathrm{C}$, and minimum $15^{\circ} \mathrm{C}$. No growth at $37^{\circ} \mathrm{C}$.

Notes. The new species nested together with S. strictum and Sarocladium bactrocephalum in a well-supported clade; however, it is distinguished from the other two species by producing chlamydospores. The phialides of $S$. strictum (up to $56 \times 2.5 \mu \mathrm{m}$ ) are larger than those of $S$. mali. S. mali can grow at $35^{\circ} \mathrm{C}$, whereas $S$. bactrocephalum cannot, and $S$. mali cannot grow at $37^{\circ} \mathrm{C}$, whereas $S$. strictum can.

Pathogenicity test. All five tested species (A. sclerotigenum, A. mali, $S$. liquanensis, $S$. terricola, and $S$. mali) caused pale to whitish spots, some with a pale to dark brown halo, on apple fruit in both field and laboratory experiments; these symptoms were similar to original symptoms (Fig. 7). The pathogens that were inoculated onto the fruit surface were reisolated from the spots, and their identity was confirmed by morphology and molecular identification, completing Koch's postulates.

For the field inoculation with no wounding, the size of spots differed with inoculation stage. Thirty days after inoculation, lesion diameter was 3 to $6 \mathrm{~mm}$ when inoculated on 10 August (Fig. 7 A3, B3, C3, D3, and E3) and 12 September (data not shown) and 1 to $2 \mathrm{~mm}$ when inoculated on 25 June (Fig. 7 A2, B2, C2, D2, and E2). For detached fruit inoculation in the laboratory accompanied by wounding, all isolates of A. sclerotigenum, A. mali, S. liquanensis, S. terricola, and $S$. mali caused dark brown spots 2 to $3 \mathrm{~mm}$ in diameter (Fig. 7 A4, B4, C4, D4, and E4). Only isolate
ACCC39311 of A. sclerotigenum caused spots without wounding at inoculation (Fig. 7 A5, B5, C5, D5, and E5).

Effects of temperature and RH on in vitro conidial germination. Temperature significantly affected conidial germination of all five tested species (A. sclerotigenum, A. mali, S. liquanensis, S. terricola, and S. mali) (Fig. 8 and Table 2). No germinated conidia were detected at $5^{\circ} \mathrm{C}$ (data not shown). Conidial germination rates differed among the tested species. A. sclerotigenum had the highest germination rate; more than two-thirds of the conidia of this species germinated from 20 to $30^{\circ} \mathrm{C}$, and the highest germination rate was $92.2 \%$ at $25^{\circ} \mathrm{C}$. A . mali reached its highest germination rate $(48.8 \%)$ at $25^{\circ} \mathrm{C}$, which was significantly higher than germination rates at the other tested temperatures $(P<0.05)$. Apart from A. terricola, which had its highest germination rate at $30^{\circ} \mathrm{C}$, the other tested species reached their highest germination rates at $25^{\circ} \mathrm{C}$.

Conidial germination rates of the five tested species increased as RH increased (Fig. 9 and Table 3). A. sclerotigenum had the highest conidia germination rates at all RH levels. In free water, it reached $92.2 \%$, and it was $65.6 \%$ at $100 \% \mathrm{RH}$. When RH was $<97 \%$, germination rates declined significantly $(P<0.05)$ from 31.9 to $2.1 \%$ (Fig. 9A). Germination rate of $A$. mali reached the highest at $100 \% \mathrm{RH}$ by $49.7 \%$, which was similar to the rate in free water $(48.8 \%)$. Additionally, the germination rate can still reach $16.6 \%$ at $97 \% \mathrm{RH}$ followed by a significant $(P<0.05)$ decline at $95 \%$ RH $(1.5 \%)$ (Fig. 9B). The same tendency can be seen in $S$. mali (Fig. 9E). For species $S$. liquanensis and S. terricola, the germination rates were above $20 \%$ when RH was $>99 \%$ followed by a significant $(P<0.05)$ decline at $97 \%$ RH (Fig. 9 C and D).

Effects of temperature and RH on infection of apple fruit. High temperature suppressed conidial germination (Table 4). Incidence of germination of A. sclerotigenum conidia was $>75 \%$ from 10 to $35^{\circ} \mathrm{C}$, reached $94.2 \%$ at $25^{\circ} \mathrm{C}$, and declined to $7.5 \%$ at $40^{\circ} \mathrm{C}$. Spots on nonwounded surfaces occurred only between 25 and $35^{\circ} \mathrm{C}$.

The effect of RH was tested at $25^{\circ} \mathrm{C}$ (Table 5). Disease incidence was affected significantly by $\mathrm{RH}$, rising as $\mathrm{RH}$ increased. Incidence was $>50 \%$ at $\mathrm{RH}>94 \%$, falling to $21.4 \%$ at $85 \% \mathrm{RH}$. Incidence of germination at $10^{\circ} \mathrm{C}$ in free water $(78.5 \%)$ exceeded that at $25^{\circ} \mathrm{C}$ and $100 \%$ RH $(72.6 \%)$.

\section{Discussion}

T. roseum, Alternaria spp., and A. sclerotigenum have been reported to be the primary causal agents of fruit spot disease on bagged apples (Guo et al. 2005; Hao et al. 2004; Li et al. 2014). Our study, based on a survey of orchards in Shaanxi Province, was consistent with previous studies in that $T$. roseum typically caused small black spots surrounding the calyx, whereas Alternaria spp. caused larger black spots that were more widely scattered on the fruit surface. In this study, we focused primarily on Acremonium-like species, which cause brown spots on the fruit surface. In our survey, A. sclerotigenum was the primary causal agent of brown spot disease, which is consistent with Li et al. (2014). However, we found that four additional Acremonium-like species could also cause brown spot disease. Based on morphological characteristics and phylogenetic analysis, we identified one of these as a new species (A. mali) belonging to

Table 2. Average percentage of in vitro conidial germination and corresponding standard errors of five isolates (based on 500 conidia) at different temperatures 12 or $16 \mathrm{~h}$ after inoculation

\begin{tabular}{|c|c|c|c|c|c|c|c|}
\hline \multirow[b]{2}{*}{ Species } & \multicolumn{7}{|c|}{ Temperature $\left({ }^{\circ} \mathrm{C}\right)$} \\
\hline & 10 & 15 & 20 & 25 & 30 & 35 & 40 \\
\hline Acremonium sclerotigenum & $1.8 \pm 0.2 \mathrm{e}^{\mathrm{y}}$ & $7.4 \pm 0.5 \mathrm{~d}$ & $68.6 \pm 3.5 \mathrm{c}$ & $92.2 \pm 1.9 \mathrm{a}$ & $80.0 \pm 1.0 \mathrm{~b}$ & $8.6 \pm 0.6 \mathrm{~d}$ & $0.2 \pm 0.1 \mathrm{e}$ \\
\hline Acremonium mali & $0.9 \pm 0.4 \mathrm{~cd}$ & $1.2 \pm 0.5 \mathrm{~cd}$ & $4.0 \pm 1.4 \mathrm{c}$ & $48.8 \pm 4.0 \mathrm{a}$ & $9.7 \pm 2.7 \mathrm{~b}$ & $4.2 \pm 3.3 \mathrm{c}$ & $0.3 \pm 0.3 \mathrm{~d}$ \\
\hline Sarocladium liquanensis & $1.4 \pm 0.5 \mathrm{c}$ & $7.2 \pm 4.4 \mathrm{bc}$ & $17.3 \pm 5.0 \mathrm{~b}$ & $45.57 \pm 13.24 \mathrm{a}$ & $16.4 \pm 1.4 \mathrm{~b}$ & $1.6 \pm 1.0 \mathrm{c}$ & $0.05 \pm 0.1 \mathrm{c}$ \\
\hline Sarocladium terricola & $2.3 \pm 0.3 \mathrm{e}$ & $3.1 \pm 0.7 \mathrm{e}$ & $19.3 \pm 1.9 \mathrm{c}$ & $26.4 \pm 3.4 \mathrm{~b}$ & $50.5 \pm 2.6 \mathrm{a}$ & $13.5 \pm 0.7 \mathrm{~d}$ & $0.3 \pm 0.5 \mathrm{e}$ \\
\hline Sarocladium mali ${ }^{\mathrm{z}}$ & $4.95 \pm 1.1 \mathrm{~d}$ & $12.3 \pm 2.8 \mathrm{c}$ & $25.54 \pm 4.3 \mathrm{~b}$ & $47.17 \pm 6.7 \mathrm{a}$ & $22.18 \pm 4.0 \mathrm{~b}$ & $12.53 \pm 2.1 \mathrm{c}$ & $0.51 \pm 0.4 \mathrm{~d}$ \\
\hline
\end{tabular}

${ }^{y}$ Means and standard errors were calculated on the basis of four replications; means in a column followed by the same letter do not differ significantly $(P<0.05)$ according to multiple comparisons of predicted values by the generalized linear model.

${ }^{\mathrm{z}}$ Species was inoculated for $16 \mathrm{~h}$. 
the genus Acremonium and two as new species in the genus Sarocladium (S. liquanensis and $S$. mali) as well as one that was a newly recorded pathogen of brown spot in China (S. terricola). The genus Sarocladium was established by Gams and Hawksworth (1975). Its morphological features are similar to the genus Acremonium, which is a large and complex polyphyletic genus of Hypocreales (Giraldo et al. 2015), and its taxonomy is chaotic based solely on its simple morphological features. The genus Sarocladium can be morphologically distinguished from the genus Acremonium by its commonly occurring adelophialides or repeatedly branched conidiophores (Summerbell et al. 2011). Based on phylogenetic analysis, the relationship between the genera Acremonium and Sarocladium was

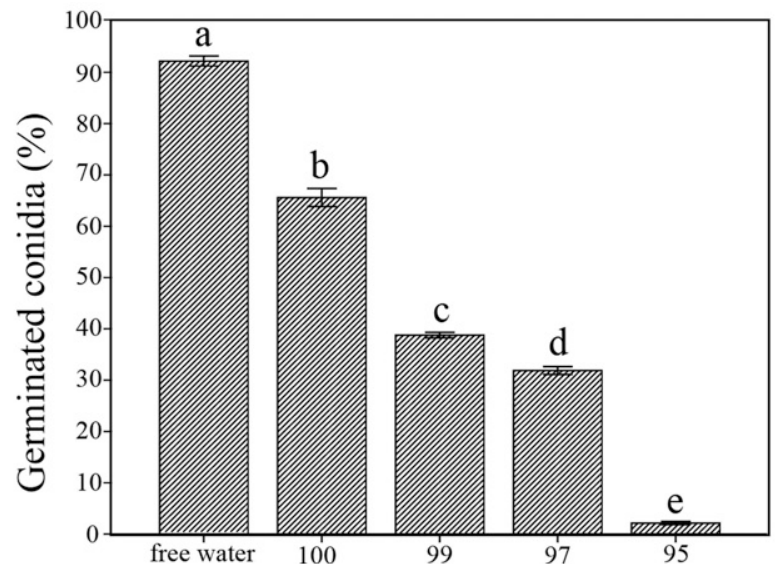

A Relative humidity (\%)

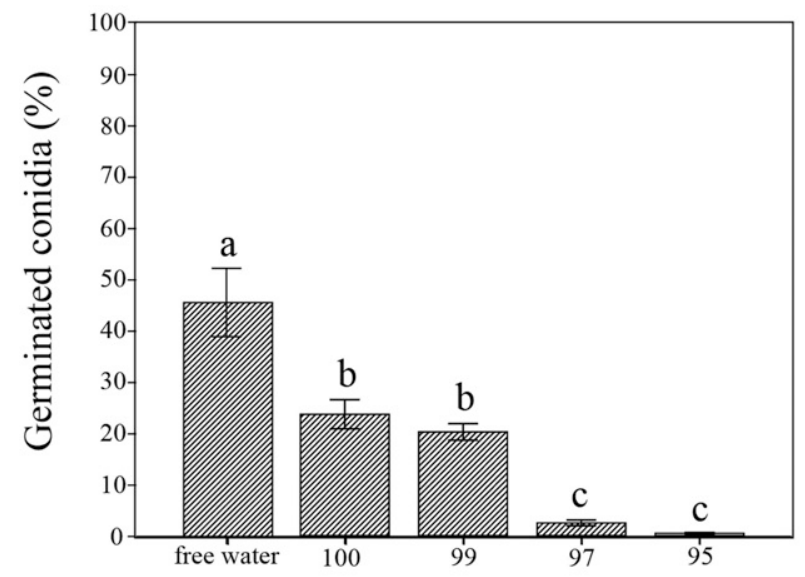

C Relative humidity (\%)

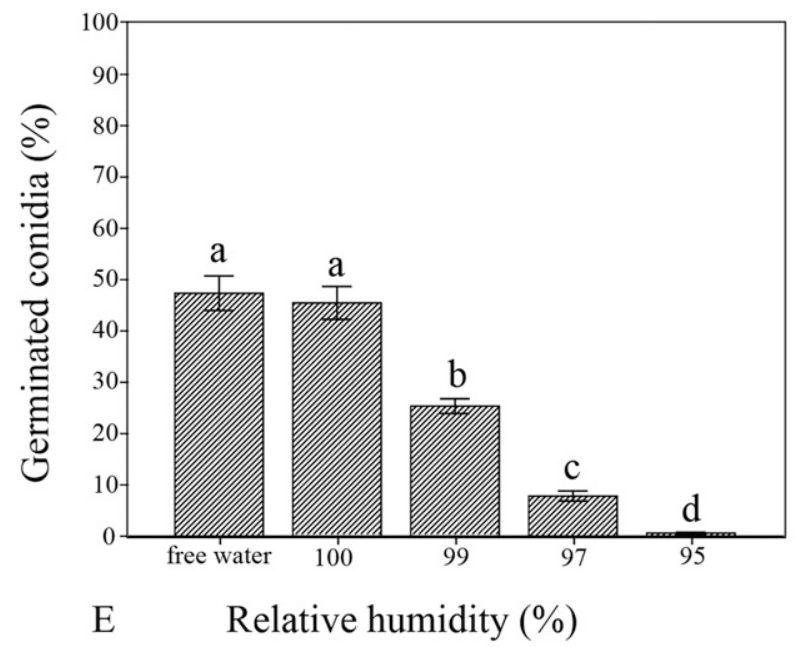

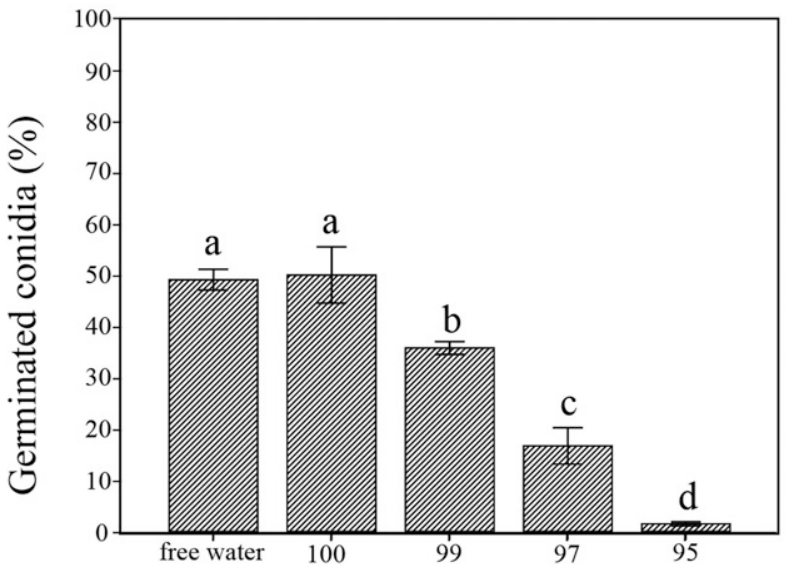

B Relative humidity (\%)

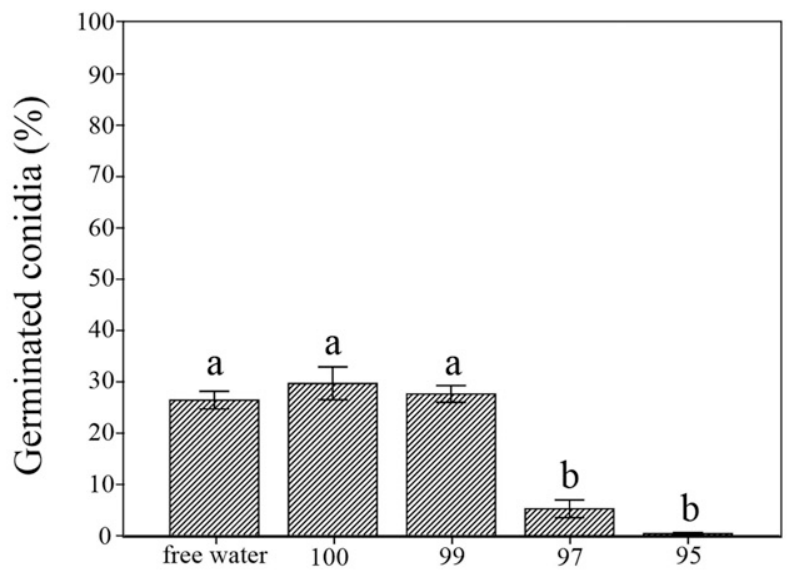

D Relative humidity (\%)

Fig. 9. Effect of relative humidity on conidial germination. The average germination rate and the corresponding standard error (calculated based on the date in Table 3 ) in each relative humidity are shown as a bar and a corresponding error bar, respectively. Different letters indicate that the germination rates were significantly different $(P<0.05)$ according to multiple comparisons of predicted values by the generalized linear model. A, Acremonium sclerotigenum ACCC 39311 (stored in Agricultural Culture Collection of China). B, Acremonium mali ACCC 39305. C, Sarocladium liquanensis ACCC 39306. D, Sarocladium terricola ACCC 39309. E, Sarocladium mali ACCC 39308. 
much clearer (Giraldo et al. 2014, 2015; Summerbell et al. 2011). In the study of Li et al. (2014), two types of strains were discovered among A. sclerotigenum that were causal agents of brown spot disease: strain 1 produced ellipsoidal to ovoid conidia assembling in slimy heads, and strain 2 produced spindle-shaped conidia in a long chain. All of our A. sclerotigenum isolates were coherent with strain 1 , whereas the description of strain 2 was similar to the species that we identified as $S$. terricola.

Most species within the genera Acremonium and Sarocladium are either saprophytic fungi in soil or pathogens of plants (Perdomo et al. 2010). Sarocladium oryzae, the type species of the genus Sarocladium, is an important plant pathogen causing sheath rot of rice (Gams and Hawksworth 1975). It is also known to produce cerulenin, a secondary metabolite that can suppress leaf blast on rice (Oryza sativa) (Ayyadurai et al. 2005; Lanoiselet et al. 2012). Some species in the genera Acremonium and Sarocladium are considered opportunistic pathogens of humans or other mammals (De Hoog et al. 2000; Guarro et al. 1997; Summerbell 2003). An increasing number and diversity of infections caused by Acremonium-like species have been reported and constitute a wide spectrum of clinical diseases (Anadolu et al. 2001; Das et al. 2010; Lopes et al. 1995). The most common anatomical sites for Acremonium and Sarocladium isolates were the respiratory tract, nails, and eye. Among these species, A. sclerotigenum was commonly isolated from blood, tracheal aspirate, and nails (Guarro et al. 2009; Novicki et al. 2003; Perdomo et al. 2010). S. terricola was usually discovered from bronchoalveolar lavage fluid and sputum, but whether it is a human pathogen is not clear (Perdomo et al. 2010). The phylogenetic relationships between isolates discovered from brown spot disease on apple fruit and the causal agents of human disease need additional study. The possibility that causal agents of brown spot disease on bagged apples may infect humans opportunistically suggests that these fungi could pose risks for immunocompromised individuals.

Brown spot disease has occurred mainly in China because of the widespread application of fruit bagging. The specialized microenvironment created by bagging seems to have played a role in inducing this disease ( $\mathrm{Li}$ et al. 2015). In this study, we found that temperature and RH had significant impact on conidial germination. The bags can help the fruit surface to retain high levels of $\mathrm{RH}$, particularly during prolonged rainy periods or wet growing seasons. From the pathogen testing in the field and laboratory, it is clear that occurrence of brown spot disease was influenced by fruit development stage and wounding of fruit. When inoculated on young fruit in June, spots were smaller (1to 2-mm diameter); in contrast, spots were larger (3- to 6-mm diameter) when fruit were inoculated at the stage of fruit enlargement (in August and September). Similar phenomena were observed in Trichotecium black spot on bagged apples by Dai at al. (2019). They speculated that infection of younger fruit introduced host resistance responses that restricted lesion development, whereas these responses were weaker when inoculation occurred at later stages of fruit development (Dai at al. 2019; Hwang 1983; Kohn et al 1983). Whether changes in the chemical composition of the fruit surface also contribute to the increased susceptibility to brown spot late in the season is a question that merits additional study. Reducing inoculum of the causal agents before covering the fruit with bags is a potentially effective approach for protecting apples from fruit spot disease; this is also a potential method to control moldy core and core rot, which are caused mainly by Alternaria alternata and $T$. roseum (Reuveni et al. 2002, 2003).

Table 3. Average percentage of in vitro conidial germination and corresponding standard errors of five isolates (based on 500 conidia) at different relative humidity at the temperature of $25^{\circ} \mathrm{C} 12$ or $16 \mathrm{~h}$ after inoculation

\begin{tabular}{|c|c|c|c|c|c|}
\hline \multirow[b]{2}{*}{ Species } & \multicolumn{5}{|c|}{ Relative humidity (\%) } \\
\hline & Free water & 100 & 99 & 97 & 95 \\
\hline Acremonium sclerotigenum & $92.2 \pm 1.9 \mathrm{a}^{\mathrm{y}}$ & $65.6 \pm 3.5 \mathrm{~b}$ & $38.8 \pm 1.1 \mathrm{c}$ & $31.9 \pm 1.5 \mathrm{~d}$ & $2.1 \pm 0.6 \mathrm{e}$ \\
\hline Acremonium mali & $48.8 \pm 4.0 \mathrm{a}$ & $49.7 \pm 10.9 \mathrm{a}$ & $35.6 \pm 2.5 \mathrm{~b}$ & $16.6 \pm 7.0 \mathrm{c}$ & $1.5 \pm 0.8 \mathrm{~d}$ \\
\hline Sarocladium liquanensis & $45.57 \pm 13.24 \mathrm{a}$ & $23.3 \pm 5.6 \mathrm{a}$ & $20.0 \pm 3.2 \mathrm{a}$ & $2.5 \pm 1.1 \mathrm{~b}$ & $0.5 \pm 0.4 b$ \\
\hline Sarocladium terricola & $26.4 \pm 3.4 \mathrm{a}$ & $29.6 \pm 6.3 \mathrm{a}$ & $27.6 \pm 3.2 \mathrm{a}$ & $5.4 \pm 3.4 \mathrm{~b}$ & $0.6 \pm 0.3 b$ \\
\hline Sarocladium mali ${ }^{\mathrm{z}}$ & $47.17 \pm 6.7 \mathrm{a}$ & $45.28 \pm 6.4 \mathrm{a}$ & $25.26 \pm 2.9 \mathrm{~b}$ & $7.82 \pm 2.0 \mathrm{c}$ & $0.62 \pm 0.4 \mathrm{~d}$ \\
\hline
\end{tabular}

${ }^{\mathrm{y}}$ Means and standard errors were calculated on the basis of four replications; means in a column followed by the same letter do not differ significantly $(P<0.05)$ according to multiple comparisons of predicted values by the generalized linear model.

${ }^{\mathrm{z}}$ Species was inoculated for $16 \mathrm{~h}$.

Table 4. Effect of temperature on infection ${ }^{\times}$

\begin{tabular}{lccccccc}
\hline & \multicolumn{7}{c}{ Temperature $\left({ }^{\circ} \mathbf{C}\right)$} \\
\cline { 2 - 7 } & $\mathbf{1 0}$ & $\mathbf{1 5}$ & $\mathbf{2 0}$ & $\mathbf{2 5}$ & $\mathbf{3 0}$ & $\mathbf{3 5}$ & $\mathbf{4 0}$ \\
\hline Incidence $(\%)$ & $78.5 \pm 4.8^{\mathrm{y}}$ & $87.3 \pm 5.0$ & $90.8 \pm 4$ & $94.2 \pm 3.4$ & $88.3 \pm 5.0$ & $85.8 \pm 3.9$ & $7.5 \pm 1.2$ \\
Diameter of fruit spots (mm) & $1-3.3$ & $1-3.1$ & $1-2.2$ & $1-3.5$ & $1-2.1$ & $1-3.4$ & 1 \\
Spots on nonwounded fruit surface & $-\mathrm{z}$ & - & - & + & + & + \\
\hline
\end{tabular}

${ }^{\mathrm{x}}$ Incidence rates and diameters of fruit spots were measured 10 days after in vitro inoculation of Acremonium sclerotigenum.

${ }^{\mathrm{y}}$ Means and standard errors were calculated on the basis of four replications.

${ }^{\mathrm{z}}$ No spot on nonwounded surface is indicated by - ; spots happened on nonwounded surface is indicated by + .

Table 5. Effect of relative humidity on infection ${ }^{\mathrm{x}}$

\begin{tabular}{|c|c|c|c|c|c|c|}
\hline & \multicolumn{6}{|c|}{ Relative humidity (\%) } \\
\hline & Free water & 100 & 98 & 94 & 85 & 75 \\
\hline Incidence $(\%)$ & $94.2 \pm 3.4^{y}$ & $72.6 \pm 7.5$ & $52.6 \pm 4.8$ & $51.1 \pm 8.2$ & $21.4 \pm 5.5$ & $9.8 \pm 2.8$ \\
\hline Diameter of fruit spots $(\mathrm{mm})$ & $1-3.5$ & $1-3.1$ & $1-2.2$ & $1-2.1$ & $1-1.8$ & $1-2.5$ \\
\hline Spots on nonwounded fruit surface & $t^{\mathrm{z}}$ & + & + & - & - & - \\
\hline
\end{tabular}

${ }^{\mathrm{x}}$ Incidence rates and diameters of fruit spots were measured 10 days after in vitro inoculation of Acremonium sclerotigenum.

${ }^{\mathrm{y}}$ Means and standard errors were calculated on the basis of four replications.

${ }^{\mathrm{z}}$ No spot on nonwounded surface is indicated by - ; spots happened on nonwounded surface is indicated by + . 


\section{Literature Cited}

Altekar, G., Dwarkadas, S., Huelsenbeck, J. P., and Ronquist, F. 2004. Parallel Metropolis coupled Markov chain Monte Carlo for Bayesian phylogenetic inference. Bioinformatics 20:407-415.

Anadolu, R., Hilmioglu, S., Oskay, T., Boyvat, A., Peksari, Y., and Gurgey, E. 2001. Indolent Acremonium strictum infection in an immunocompetent patient. Int. J. Dermatol. 40:451-453.

Ayyadurai, N., Kirubakaran, S. I., Srisha, S., and Sakthivel, N. 2005. Biological and molecular variability of Sarocladium oryzae, the sheath rot pathogen of rice (Oryza sativa L.). Curr. Microbiol. 50:319-323.

Batzer, J. C., Gleason, M. L., Harrington, T. C., and Tiffany, L. H. 2005. Expansion of the sooty blotch and flyspeck complex on apples based on analysis of ribosomal DNA gene sequences and morphology. Mycologia 97:1268-1286.

Carbone, I., and Kohn, L. M. 1999. A method for designing primer sets for speciation studies in filamentous ascomycetes. Mycologia 91:553-556.

Cruse, M., Telerant, R., Gallagher, T., Lee, T., and Taylor, J. W. 2002. Cryptic species in Stachybotrys chartarum. Mycologia 94:814-822.

Cubeta, M. A., Echandi, E., Abernethy, T., and Vilgalys, R. 1991. Characterization of anastomosis groups of binucleate Rhizoctonia species using restriction analysis of an amplified ribosomal RNA gene. Mol. Plant Pathol. 81:1395-1400.

Dai, P., Liang, X., Wang, Y., Gleason, M. L., Zhang, R., and Sun, G. Y. 2019. High humidity and age-dependent fruit susceptibility promote development of Trichothecium black spot on apple. Plant Dis. 103:259-267.

Das, S., Saha, R., Dar, S. A., and Ramachandran, V. G. 2010. Acremonium species: A review of the etiological agents of emerging hyalohyphomycosis. Mycopathologia 170:361-375.

De Hoog, G. S., Guarro, J., Gené, J., and Figueras, M. J. 2000. Atlas of Clinical Fungi, 2nd Ed. Centraalbureau voor Schimmelcultures/University Rovira I Virgili, Reus, Spain.

Gams, W., and Hawksworth, D. L. 1975. The identity of Acrocylindrium oryzae Sawada and a similar fungus causing sheath-rot of rice. Kavaka 3:57-61.

Giraldo, A., Gené, J., Cano, J., de Hoog, G., Decock, C., and Guarro, J. 2014. Acremonium with catenate elongate conidia: Phylogeny of Acremonium fusidioides and related species. Mycologia 106:328-338.

Giraldo, A., Gené, J., Sutton, D. A., Madrid, H., de Hoog, G. S., Cano, J., Decock, C., Crous, P. W., and Guarro, J. 2015. Phylogeny of Sarocladium (Hypocreales). Persoonia 34:10-24.

Groenewald, J. Z., Nakashima, C., Nishikawa, J., Shin, H.-D., Park, J. H., Jama, A. N., Groenewald, M., Braun, U., and Crous, P. W. 2013. Species concepts in Cercospora: Spotting the weed among the roses. Stud. Mycol. 75:115-170.

Guarro, J., Gams, W., Pujol, I., and Gené, J. 1997. Acremonium species: New emerging opportunists-in vitro antifungal susceptibilities and review. Clin. Infect. Dis. 25:1222-1229.

Guarro, J., Palacio, A., Gené, J., Cano, J., and Gómez, C. 2009. A case of colonization of a prosthetic mitral valve by Acremonium strictum. Rev. Iberoam. Micol. 26:146-148.

Guo, Y. Z., Sun, G. Y., Gao, B. W., Li, C. Y., Zhang, P. L., and Lei, X. L. 2005. Studies on the identification of pathogen and the biological characteristics of black-dot disease of bagged apple. Acta Agric. Boreali-Occident. Sin. 14(3):18-21.

Hall, T. A. 1999. BioEdit:a user-friendly biological sequence alignment editor and analysis program for Windows 95/98/NT. Nucleic Acids Symposium Series 41:95-98.

Hao, X. A., Wu, Y. F., Zhou, X. M., Yang, Y., Wang, X. M., and Liu, S. B. 2004. Preliminary studies on the identification and occurrence of black-dot disease on bagged apple fruit in Shaanxi. Acta Agric. Boreali-Occident. Sin. 13(4):54-57.

Harris, R. F., Gardner, W. R., Adebayo, A. A., and Sommers, L. E. 1970. Agar dish isopiestic equilibration method for controlling the water potential of solid substrates. Appl. Microbiol. 19:536-537.

Hwang, B. K. 1983. Contents of sugars, fruit acids, amino acids and phenolic compounds of apple fruits in relation to their susceptibility to Botryosphaeria ribis. J. Phytopathol. 108:1-11.

Kohn, F. C., and Hendrix, Fss. F. 1983. Influence of sugar content and pH on development of white rot on apples. Plant Dis. 67:410-412.

Lang, A. R. G. 1967. Osmotic coefficients and water potentials of sodium chloride solutions from 0 to $40^{\circ} \mathrm{C}$. Aust. J. Chem. 20:2017-2023.

Lanoiselet, V., You, M. P., Li, Y. P., Wang, C. P., Shivas, R. G., and Barbetti, M. J. 2012. First report of Sarocladium oryzae causing sheath rot on rice (Oryza sativa) in Western Australia. Plant Dis. 96:1382.
Li, B. H., Wang, C. C., Dong, X. L., Zhang, Z. F., and Wang, C. X. 2014 Acremonium brown spot, a new disease caused by Acremonium sclerotigenum on bagged apple fruit in China. Plant Dis. 98:1012.

Li, H. Y., Sun, G. Y., Batzer, J. C., Crous, P. W., Groenewald, J. Z., Karakaya, A., and Gleason, M. L. 2011. Scleroramularia gen. nov. associated with sooty blotch and flyspeck of apple and pawpaw from the Northern Hemisphere. Fungal Divers. 46:53-66.

Li, X. M., Li, J., Li, Q. L., Huang, J. B., Meng, L. F., and Yu, J. 2015. Effects of rainfall in different months on bagged apple black rot disease. Chin. Agric. Sci. Bull. 31(4):217-221.

Lopes, J. O., Kolling, L. C., and Neumaier, W. 1995. Kerion like lesion of the scalp due to Acremonium kiliense in a noncompromised boy. Rev. Inst. Med. Trop. São Paulo 37:365-368.

Novicki, T. J., Geise, R., Limaye, A. P., Lafe, K., Bui, U., and Cookson, B. T. 2003. Genetic diversity among clinical isolates of Acremonium strictum determined during an investigation of a fatal mycosis. J. Clin. Microbiol. 41: 2623-2628.

Nylander, J. A. A. 2004. MrModeltest v2. Uppsala University, Evolutionary Biology Centre, Uppsala, Sweden.

Page, R. D. M. 1996. TreeView: An application to display phylogenetic trees on personal computers. Comput. Appl. Biosci. 12:357-358.

Perdomo, H., Sutton, D. A., García, D., Fothergill, A. W., Cano, J., Gené, J., and Summerbell, R. C. 2010. Spectrum of clinically relevant Acremonium species in United States. J. Clin. Microbiol. 49:243-256.

Reuveni, M., Sheglov, D., and Cohen, Y. 2003. Control of moldy-core decay in apple fruits by $\beta$-aminobutyric acids and potassium phosphites. Plant Dis. 87: 933-936.

Reuveni, M., Sheglov, D., Sheglov, N., Ben-Arie, R., and Prusky, D. 2002. Sensitivity of Red Delicious apple fruit at various phenologic stages to infection by Alternaria alternata and moldy-core control. Eur. J. Plant Pathol. 108:421-427.

Rockland, L. B. 1960. Saturated salt solutions for static control of relative humidity between 5 and $40^{\circ}$ C. Anal. Chem. 32:1375-1376.

Stamatakis, A., Hoover, P., and Rougemont, J. 2008. A rapid bootstrap algorithm for the RAxML web-servers. Syst. Biol. 57:758-771.

Stamatakis, A., Ludwig, T., and Meier, H. 2005. RAxML-III: A fast program for maximum likelihood-based inference of large phylogenetic trees. Bioinformatics 21:456-463.

Summerbell, R. C. 2003. Aspergillus, Fusarium, Sprothrix, Piedraia, and their relatives. Pages 237-498 in: Pathogenic Fungi in Humans and Animals, 2nd Ed. D. H. Howard, ed. Marcel Dekker, New York, NY.

Summerbell, R. C., Gueidan, C., Schroers, H. J., de Hoog, G. S., Starink, M., Arocha Rosete, Y., Guarro, J., and Scott, J. A. 2011. Acremonium phylogenetic overview and revision of Glimastix, Sarocladium, and Trichothecium. Stud. Mycol. 68:139-162.

Swofford, D. L. 2003. PAUP*. Phylogenetic Analysis Using Parsimony (* and Other Methods). Version 4.0. Sinauer Associates, Sunderland, MA.

Vilgalys, R., and Hester, M. 1990. Rapid genetic identification and mapping of enzymatically amplified ribosomal DNA from several Cryptococcus species. J. Bact. 172:4238-4246.

Wang, B., Li, B. H., Dong, X. L., Wang, C. X., and Zhang, Z. F. 2015. Effects of temperature, wetness duration, and moisture on the conidial germination, infection, and disease incubation period of Glomerella cingulata. Plant Dis. 99:249-256.

Wang, J. Q., Ma, J. H., Sun, J. X., Luan, B. H., and Ren, Q. 2007. Research progress on spotted-scar diseases of bagged apple fruit. J. Anhui Agr. 35: 2941-2943

White, T. J., Bruns, T. D., Lee, S., and Taylor, J. W. 1990. Amplification and direct sequencing of fungal ribosomal RNA genes for phylogenetics. Pages 315-322 in: PCR Protocols: A Guide to Methods and Applications. M. A. Innis, D. H. Gelfand, J. J. Sninsky, and T. J. White, eds. Academic Press, San Diego, CA.

Wiseman, M. S., Dugan, F. M., Kim, Y. K., and Xiao, C. L. 2015. A postharvest fruit rot of apple caused by Lambertella corni-maris in Washington State. Plant Dis. 99:201-206.

Xu, B. L., Wei, Z. Z., and Wang, X. L. 2000. Symptoms and identification of black spot disease on apple fruit. Plant Prot. 26(5):6-8. 